\title{
Lexis
}

Journal in English Lexicology

$9 \mid 2015$

Utterer-Centered Studies on Lexical Issues

\section{Pronunciation of Prefixed Words in Speech: The Importance of Semantic and Intersubjective}

\section{Parameters}

\section{Nicolas Videau and Sylvie Hanote}

\section{(2) OpenEdition \\ Journals}

Electronic version

URL: http://journals.openedition.org/lexis/982

DOI: $10.4000 /$ lexis.982

ISSN: 1951-6215

\section{Publisher}

Université Jean Moulin - Lyon 3

\section{Electronic reference}

Nicolas Videau and Sylvie Hanote, « Pronunciation of Prefixed Words in Speech: The Importance of Semantic and Intersubjective Parameters », Lexis [Online], 9 | 2015, Online since 13 May 2015,

connection on 19 April 2019. URL : http://journals.openedition.org/lexis/982 ; DOI : 10.4000/lexis.982

This text was automatically generated on 19 April 2019.

\section{(c) (i) (9)}

Lexis is licensed under a Creative Commons Attribution-NonCommercial-NoDerivatives 4.0 International License. 


\title{
Pronunciation of Prefixed Words in Speech: The Importance of Semantic and Intersubjective Parameters
}

\author{
Nicolas Videau and Sylvie Hanote
}

\section{Introduction}

1 Numerous studies on prefixed words have been carried out by lexicologists (see Aronoff [1976], Bauer [1983], Tournier [1985, 1991a and 1991b], Paillard [2000], among others) and by morphophonologists (see for instance Guierre [1979 and 1984], Guyot-Talbot [2003], Trevian [2003 and 2010]) and the pronunciation of prefixed words in contemporary English is traditionally based on the distinction between separable prefixes and inseparable prefixes. The theoretical framework developed by Guierre [1979] states that a separable prefix attaches to a free root and that the meaning of the newly-formed word is compositional, i.e., its meaning is determined by the meaning of the prefix and the meaning of the base. For instance, re- in rewrite is a separable prefix because it is attached to the verbal root write and because rewrite means "write again". On the other hand, an inseparable prefix attaches to a bound root. In a verb such as receive, the prefix re-is said to be inseparable because -ceive is a Latinate root that has no meaning of its own in contemporary English. This morphological distinction has phonological and phonetic consequences: a separable prefix bears secondary stress and in the case of open syllable prefixes such as re- or de-, it is pronounced with a tense vowel (e.g., rewrite [,ri:'rart]). Conversely, an inseparable prefix tends to remain unstressed and is generally pronounced with a short vowel (e.g., receive [ri'si:v]) ${ }^{1}$

2 However, this theoretical approach may prove unsatisfactory as far as the pronunciation of prefixed words in normal speech is concerned. For example, the prefix de-in a verb such as decrease is often stressed and pronounced with a tense vowel ${ }^{2}$, despite the fact that it is an inseparable prefix, in Guierre's theory. Other parameters, such as the 
semantic transparency of the prefix, the context of the utterance, the speaker's intention as well as his/her relationship with the hearer have to be taken into account.

In this paper, we look at the pronunciation of prefixed words in the "Corpus Parole", an 80,000 word speech corpus compiled at the University of Poitiers, which includes news reports, debates, interviews and political speeches drawn from $B B C$ Radio $4^{3}$ for British English and the National Public Radio ${ }^{4}$ for American English. Each example is analysed with Praat software ${ }^{5}$.

First we will analyse examples in which prefixes attach to free roots and show various degrees of prominence; they usually bear secondary stress but may also be overaccented in speech. We will show that linguistic and extra-linguistic parameters need to be considered to account for their pronunciation. We will also see that, in some cases, the prefix may undergo destressing, thus occasionally leading to semantic ambiguity. We will go on to focus on various cases of contrast, either explicit or implicit, and show how inseparable prefixes can be made prominent despite their morphological and semantic opacity. Finally we will concentrate on cases where the prefix (separable or inseparable) is prominent due to pragmatic reasons.

\section{Prefixed words in speech and semantic transparency}

\subsection{Separable prefixes associated to free roots}

Separable prefixation (i.e the combination of a free root with a separable prefix) is semantically transparent as the root is recognizable (it occurs independently) and the prefix has a full meaning. This is the case of rewrite mentioned in the introduction; it is also the case of the words decode meaning 'decipher or translate a coded message' in example (1) and rebuild meaning 'build again or differently' in example (2)):

(1) Huw Williams: the words are from a hymn to St John the Baptist but the claim is that every note of the tune has been transcribed and decoded from the stones here (BBC - Words in the News, May $\left.2^{\text {nd }}, 2007\right)$

(2) David Cameron: one of the tasks that we clearly have is to rebuild trust in our political system (BBC - David Cameron's first speech as Prime Minister, May $\left.11^{\text {th }}, 2010\right)$

Figure 1 : decoded

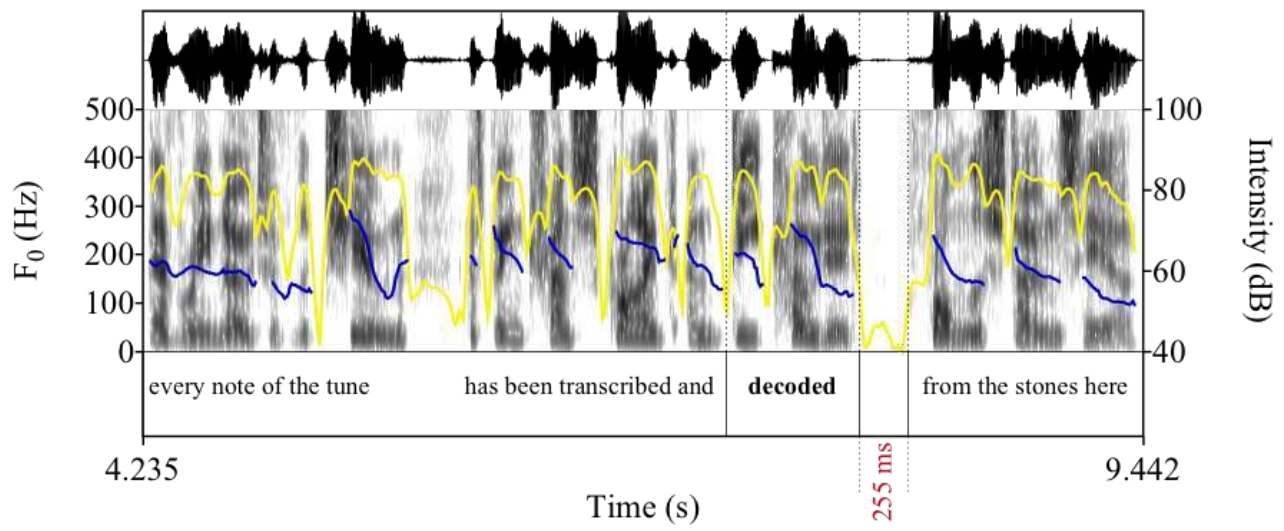


Figure 2: rebuild trust

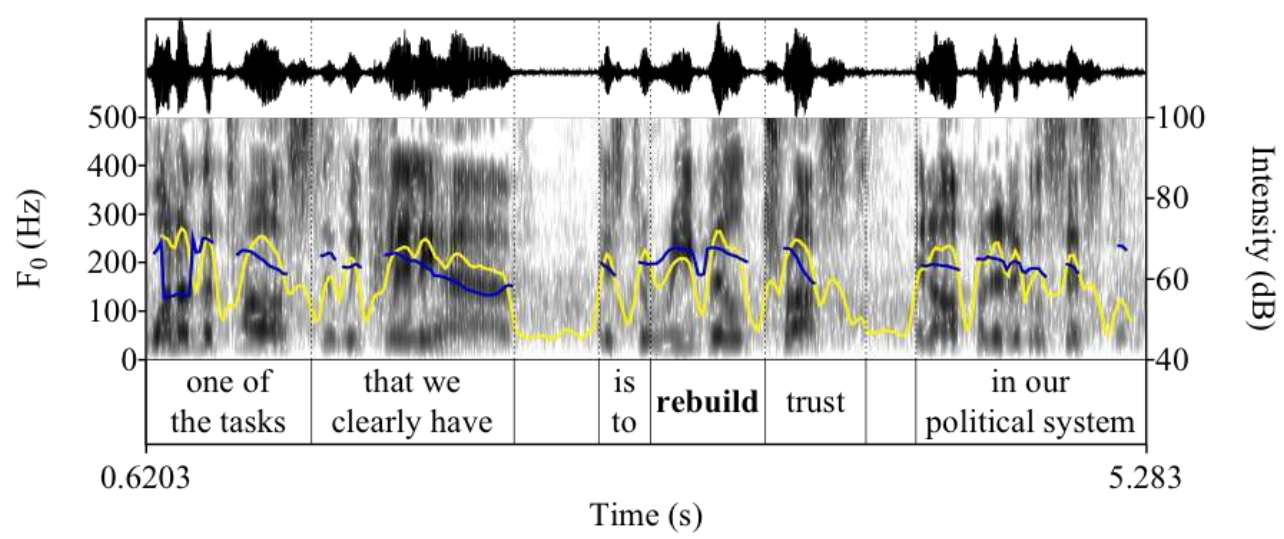

6 As shown in figures (1) and (2), there is a high degree of intensity on the prefix and on the $\operatorname{root}^{6}$ and the same movement in the $\mathrm{F}_{0}$ curve (fall) both on the prefix and on the root occurs. As far as the segmental features are concerned (see figures 3 and 4 below), the vowel <e> in de- and $r e$-is tense $\mathrm{e}^{7}$ and long. ${ }^{8}$. These data show that both the prefix and the root bear a certain degree of stress: a primary stress on the free root and a secondary stress on the separable prefix leading to the following stress patterns: decoded /210/; rebuild $/ 21 /$.

Figure 3: decoded

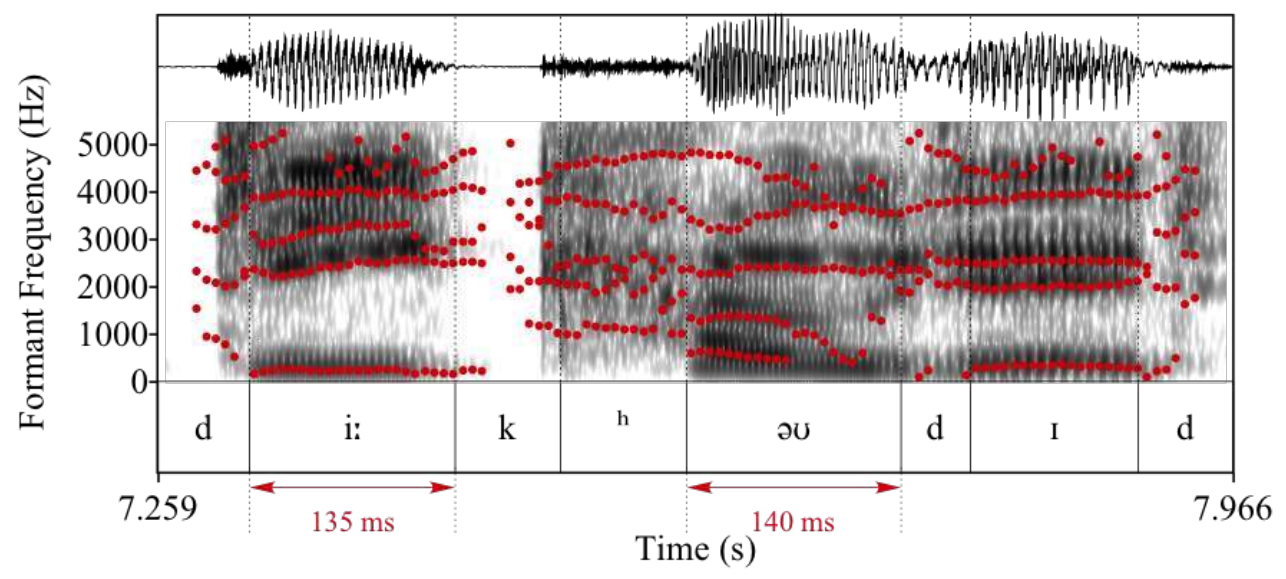




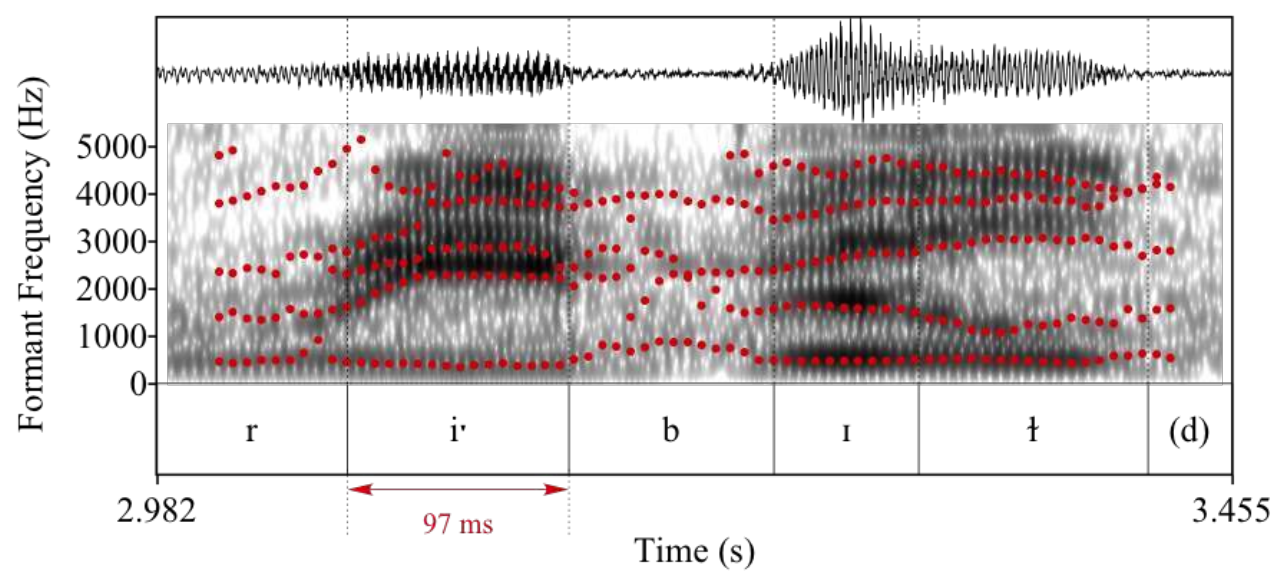

7 It should be noted that these data are not exactly identical in the two examples. For instance, the vowel of the prefix is longer in decoded than in rebuild; this can be explained by the position of the two prefixed words in the intonation phrases (IP) they belong to: in example (1), decoded is the last word of the IP and is followed by a short pause ${ }^{9}$; it is the nucleus of the IP and thus bears not only lexical stress but also nuclear accent whereas in example (2), it is the noun trust -the syntactic object of the prefixed verb- that bears the nuclear accent.

These two examples are good illustrations of the way prefixed words are uttered in speech when a separable prefix is attached to a free root, the pronunciation of the word is then in accordance with its morphology and reflects the transparency of the semantic link between the two parts of the word (the prefix and the free root). This close interaction between pronunciation, morphology and semantic transparency is probably even more obvious in words that are coined by the speaker during his/her speech as is the case of the words demothing and decreaturing in example (3) presented in the next section.

\subsection{The particular cases of neologisms formed with a separable prefix and a free root}

9 As mentioned previously, a separable prefix will bear lexical stress (usually secondary stress) when it is separable, i.e., when it attaches to a free root and when the meaning of the newly-formed word is compositional. This is the case of the words decreaturing and demothing in example (3) which were coined by the speaker during her speech to describe an unusual situation that she had to cope with:

(3) Helen Clitheroe: Kenya was... was pretty bad. We were... plagued, I think is the word, with er grasshoppers, giant moths. It was like being in a bush tucker trial ${ }^{10}$ sometimes. I was sharing a room with Paula Radcliffe. We got quite adept at, er, demothing and decreaturing our room and shoes and everything before we went training, so yeah, it was quite an experience. (BBC - Today Programme, March $31^{\text {st }}, 2012$ )

The two verbs demoth and decreature are morphologically and semantically transparent; they are formed with the privative prefix de-denoting removal or reversal and the two 
nouns moth and creature and the meaning of the resulting verbs is compositional = 'get rid of X (= moths / creatures)'. Let us look at how they are pronounced in speech.

Figure 5: demothing and decreaturing

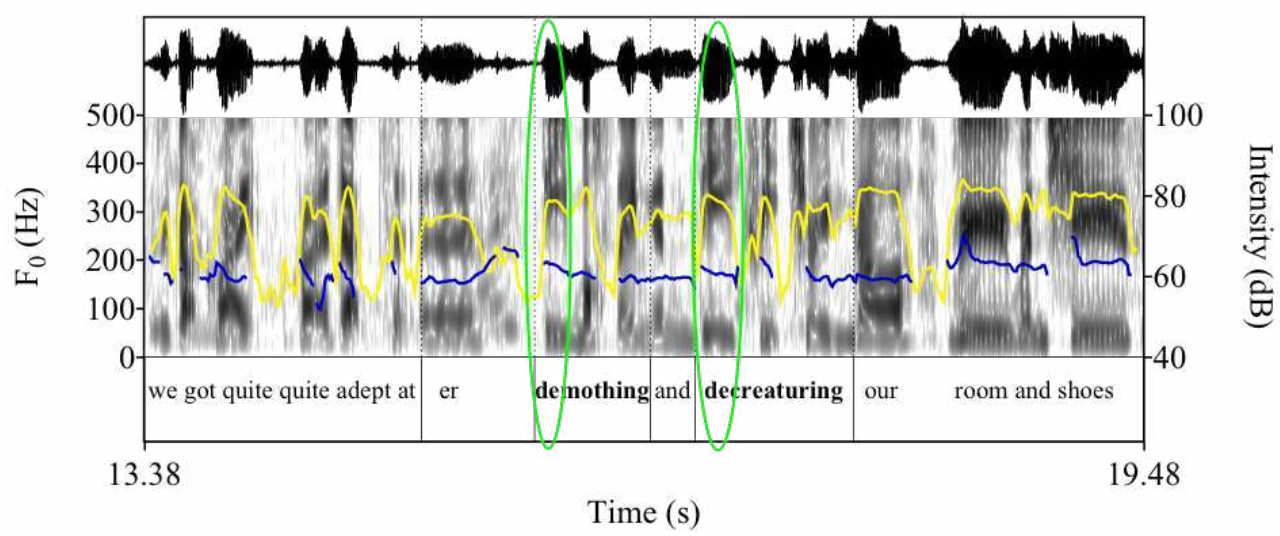

First of all, it should be noted that the two words that are prominent in this example are the nouns room and shoes which form the nucleus of the IP. Nevertheless, as far as the two -ing forms (demothing and decreaturing) are concerned, figure 5 shows that there is high intensity on the prefix de-in both cases -compared to the level of intensity that directly precedes them (on the two unstressed words er and and)- and a specific movement in the $\mathrm{F}_{0}$ curve, which makes the prefix particularly prominent in speech. One should add that in demothing, the prefix is not only stressed as in the examples presented in the previous section but it also bears the highest degree of stress in the word (the word has undergone stress-shift and its stress pattern is /120/), which is not the case in decreaturing where the root bears primary stress leading to the following stress pattern /2100/.

This difference in the stress patterns of these two words may be explained by the difference in their syllabic weight (3 syllables in demothing, 4 syllables in decreaturing) but more probably by the fact that a/ the prefixation of the hyperonym decreature is more problematic than the prefixation of demoth, semantically and morphologically close to delouse or debug ${ }^{11}$, and $\mathrm{b}$ / the prefix has already been particularly prominent in demothing; it therefore doesn't need to be overaccented in its second use (decreaturing) for the hearer to perceive it. This seems to be confirmed by the segmental data.

As far as the segmental features are concerned, the vowels of the prefix $<$ de-> in these two words are tense ${ }^{12}$ and long ${ }^{13}$ (see figures 6 and 7 below): 


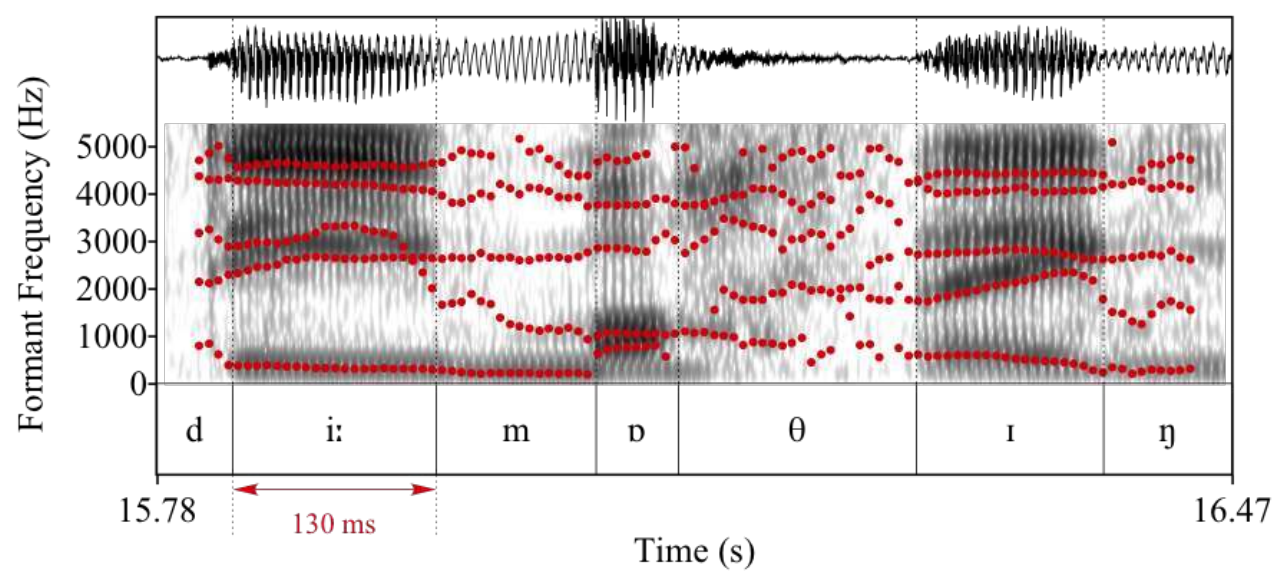

Figure 7: decreaturing

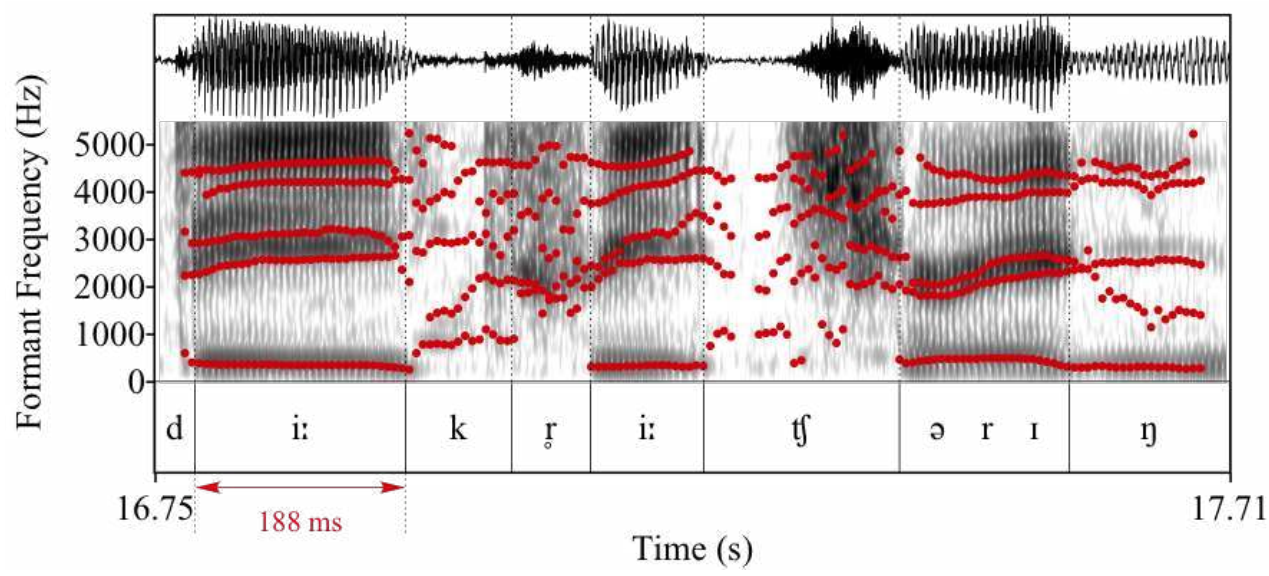

14 There may be various reasons for the prominence of the prefixes in these two words and for the lengthening of their vowels. Such features could be linked to the fact that the speaker wants to insist on the compositionality of the words for the hearer to be able to process the meaning of the newly-formed words. But in this context, they are more likely to be associated with some hesitation on the part of the speaker who is searching for the appropriate words to describe the situation; this is shown by the use of the hesitation marker er filling the pause before demothing and by the overaccentuation of the prefix in this word. There is no such filler before decreaturing but the hesitation is then coded in the extra length of the vowel of the prefix, with the speaker thinking of the root she is going to attach to it; this might also explain why the root bears primary stress here. However, the lengthening of the vowel of the prefixes in these two words gives the impression of a complete independence of the prefix from its root and helps the hearer to understand the compositional meaning of these two words and the semantic relationship between the two morphemes (the prefix and the root).

The notion of semantic transparency and its impact on the pronunciation of the word is also central in the following example:

(4) Neal Conan: An email from Julia in Iowa: "One of my friends who is mainly my online friend after he moved to Minnesota took his own life two years ago. His Facebook page remained as a macabre memorial. It is very 
disturbing when Facebook suggests that I reconnect with him. But I almost feel as though it would sully his memory if I unfriend his profile." So that's something else I hadn't thought of. (NPR - Talk of the Nation, June $9^{\text {th }}, 2010$ )

Figure 8: unfriend

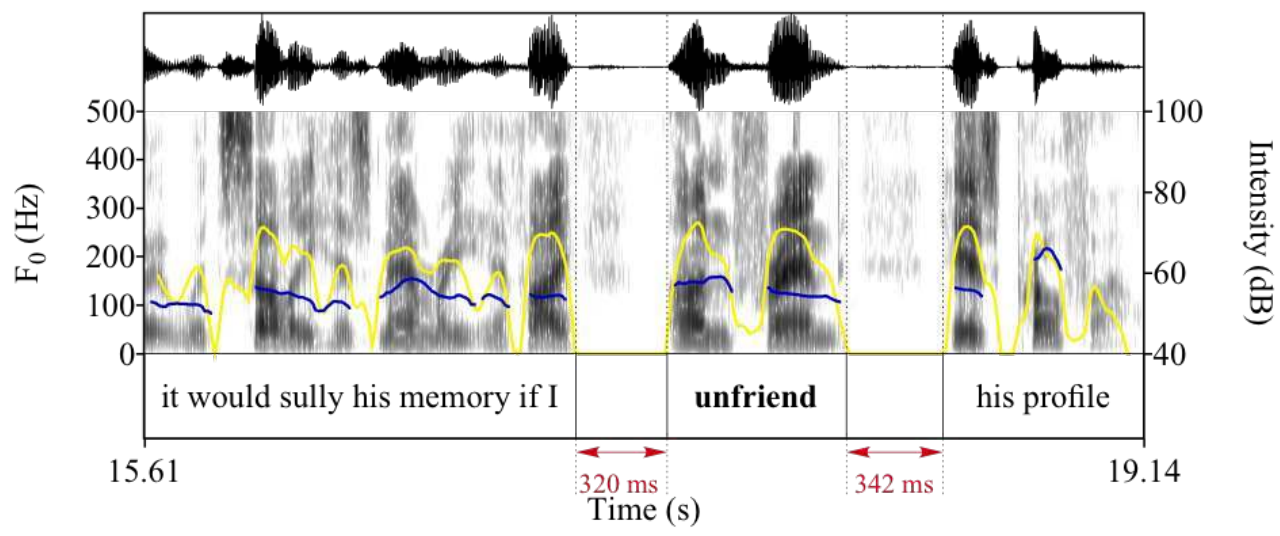

16 The verb unfriend ${ }^{14}$, which appeared with the advent of social networking sites such as Facebook, is formed with the prefix un- and the verb friend ("add (a person) to a list of friends or contacts on a social networking web site ${ }^{15 ")}$. The verb unfriend means "remove (a person) from a list of friends or contacts on a social networking web site"). It should be noted that in this example, the word appears in reported speech. The journalist is reading an email that was sent by a listener of the radio show. The whole word itself is prominent in this utterance, as it is preceded and followed by two pauses in the speech chain. One possible explanation for the first pause (320ms) could be that the journalist wants listeners to be prepared for a word they have probably rarely or never encountered. Another explanation would be that this pause shows the speaker's surprise as he reads the word. The second pause (342ms) allows the listener to process the meaning of this new word. At the word level, the prefix is made prominent through high pitch and high intensity, but also through the length of its vowel (127ms, see figure 9 below). This is indeed an uncommon duration for the lax vowel $[\Lambda]$.

Figure 9: unfriend

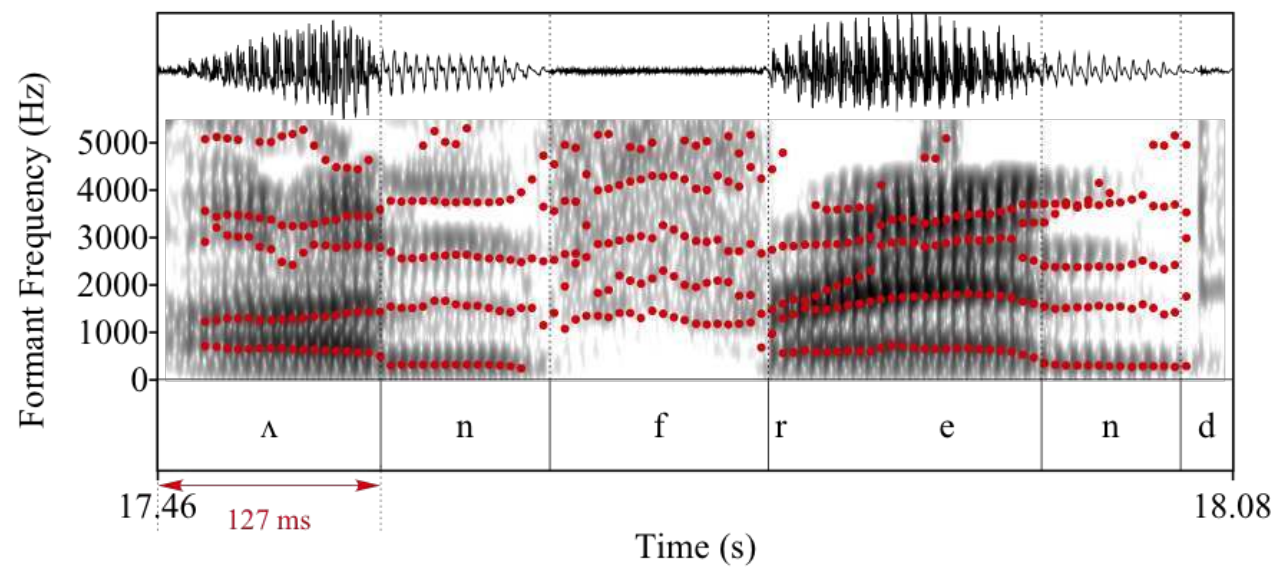

To conclude these two sections on the pronunciation of separable prefixes attached to free roots, it should be noted that in many of the examples drawn from our corpus, the 
prefixes are phonetically and prosodically stressed, bearing either secondary or primary stress. The status of separable prefixes has been described by linguists such as Guierre [1984: 38] as follows:

Like an ordinary word, a separable prefix is basically fully stressed /1/. [...] In fact the combination Sep.Pref + Stem has two stress-patterns in both of which the stem keeps its own original stress-pattern.

a/ A contrastive stress-pattern with strong contrastive stress /1/ on the prefix as well as on the stem. This pattern emphasizes the prefix and therefore allows the otherwise irregular succession of two strong stresses.

b/ A neutral or non-contrastive stress-pattern in which the prefix is destresssed /0/ or /2/ in accordance with the rhythmic constraints.

In several examples of our corpus, the prefix has indeed undergone destressing; this is the case of examples (5) to (6) dealt with in the next section. The prefix is then phonetically reduced and this phonetic process may sometimes lead to semantic ambiguity.

\subsection{Destressing and semantic ambiguity}

(5) David Cameron: A coalition will throw up all sorts of challenges, but I believe together we can provide that strong and stable Government that our country needs based on those values, rebuilding family, rebuilding community, above all rebuilding responsibility in our country. (BBC, May 11 th, 2010)

Figure 10: rebuilding

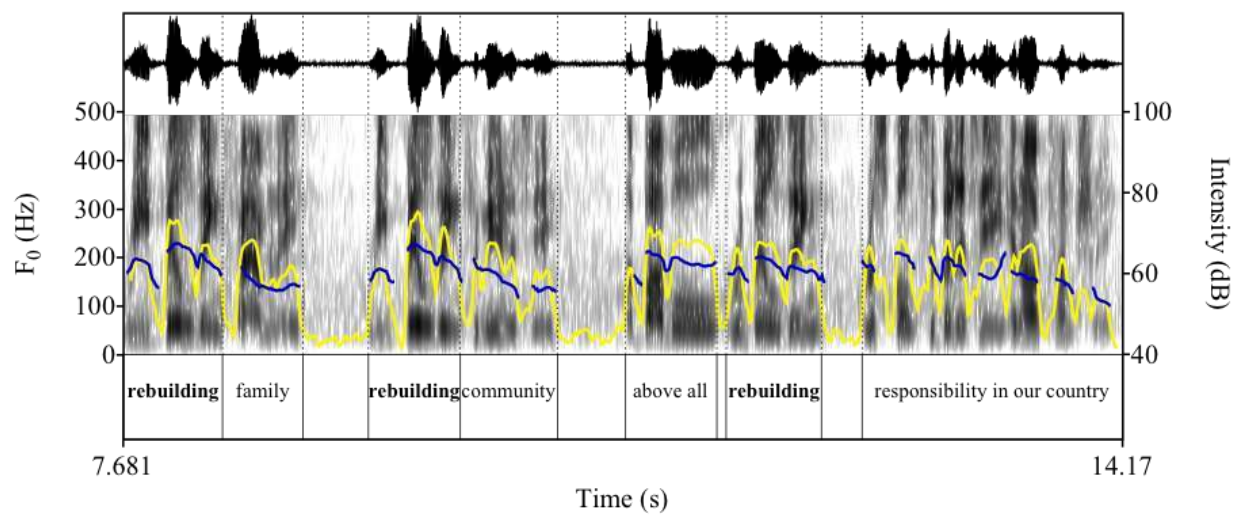

In this example drawn from the same document as example (2), the first occurrence of rebuilding is pronounced with a stressed prefix [ri:] and the length of the vowel is $12 \mathrm{~ms}$; in the second occurrence, the vowel is still phonetically in a full form but its length is $10 \mathrm{~ms}$ and in the third occurrence, the prefix is reduced (pronounced [rə], see figure 11). The destressing of the prefix is very probably linked to the repetition of the verb, the crucial information being expressed not through the verb itself but through the adverb clause above all which directly precedes it and through the direct object of the verb responsibility (in our country) which is the culminating point of the list after family and community. 


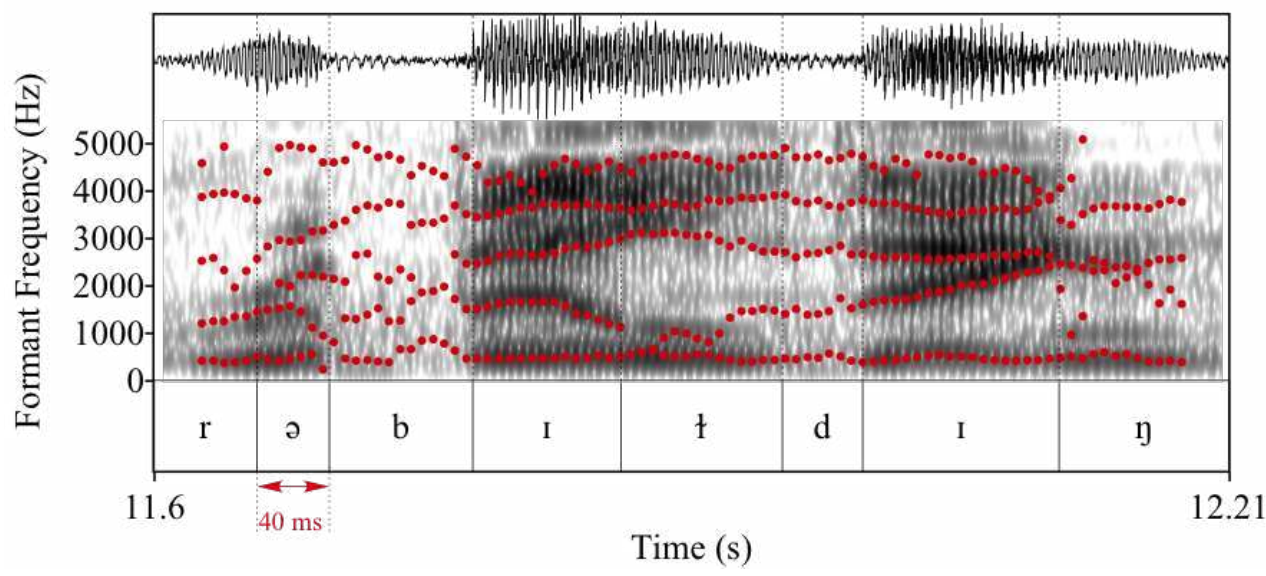

The prefix is also reduced in example (6) where the analysis cannot be the same since there is no repetition of the verb rebuild. The speaker, who used to live in New Orleans, is talking about his return, four years after Hurricane Katrina destroyed his city:

(6) PJ Hanne: It dawned on me one day. It's like... city's not gonna rebuild itself, it needs people. We need to like, you know, get in there so all right like I'm coming back you know. (NPR - Morning Edition, August 31 $1^{\text {st }}, 2009$ )

In this example, the prefix <re-> in rebuild is completely reduced: the formantic values of $F_{1}(500 \mathrm{~Hz})$ and $F_{2}(1800 \mathrm{~Hz})$ correspond to those of the weak vowel [ə]. Furthermore, this vowel is so short that it seems fused with the initial approximant $[\mathrm{r}]$ of the prefix (see figure 12). The duration of the prefix is $50 \mathrm{~ms}^{16}$, which is extremely low. Given that rebuild is a separable prefixed verb, such a pronunciation is surprising. It should also be noted that this pronunciation does not appear in dictionaries such as the Longman Pronunciation Dictionary (LPD).

Figure 12: rebuild

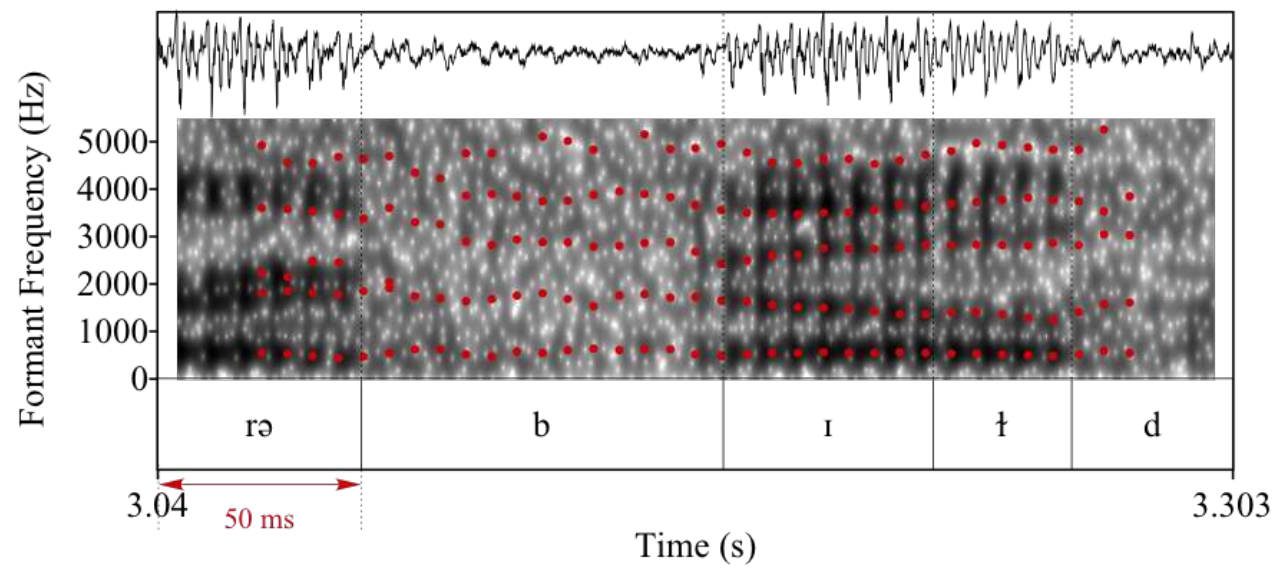

This lack of morphological transparency in the verb can be justified by the following hypothesis: the speaker uses the verb rebuild, the frequency of which is so high in the context of post-Katrina New Orleans that it may even be higher than that of the verb build itself. Thus, rebuild may be regarded as a verb that does not derive from build, but rather, as a totally separate entity. 
In examples (5) and (6), the destressing of the separable prefix <re-> does not lead to semantic ambiguity in their specific linguistic and extralinguistic contexts; it is a different matter in the two examples below where the phonetic reduction may lead to misinterpretation. This is particularly true in example (7) where there might be some ambiguity:

(7) Jane Little: This year the talk shows seized upon a decision by the airport authorities in Seattle to remove all Christmas trees because a Jewish rabbi threatened to sue them if they didn't also display a Menorah, a religious symbol for the Jewish festival of Hanukkah that coincides with the Christmas season. There was an outcry; the rabbi insisted he never wanted the trees removed, and they were replaced when the lawsuit threat was withdrawn. (BBC - Words in the News, December 21 $1^{\text {st }}, 2006$ )

This example refers to an incident linked to the presence of Christmas trees in an airport in Seattle. The Christmas trees were removed for religious reasons, then put back where they were in the first place when the lawsuit threat was withdrawn. So the verb that was meant here was re-place [,ri:' pleIs] (to restore to a previous place or position; to put back again in a place) and not replace [rI'pleIs] (to remove something from its place and put some new thing there), which is very close except for the pronunciation of the prefix (separable in the first case but inseparable in the second one). The problem here is that the prefix was said with a short vowel (57ms) and formantic values corresponding to [I], see figure (13).

Figure 13: replaced $^{17}$

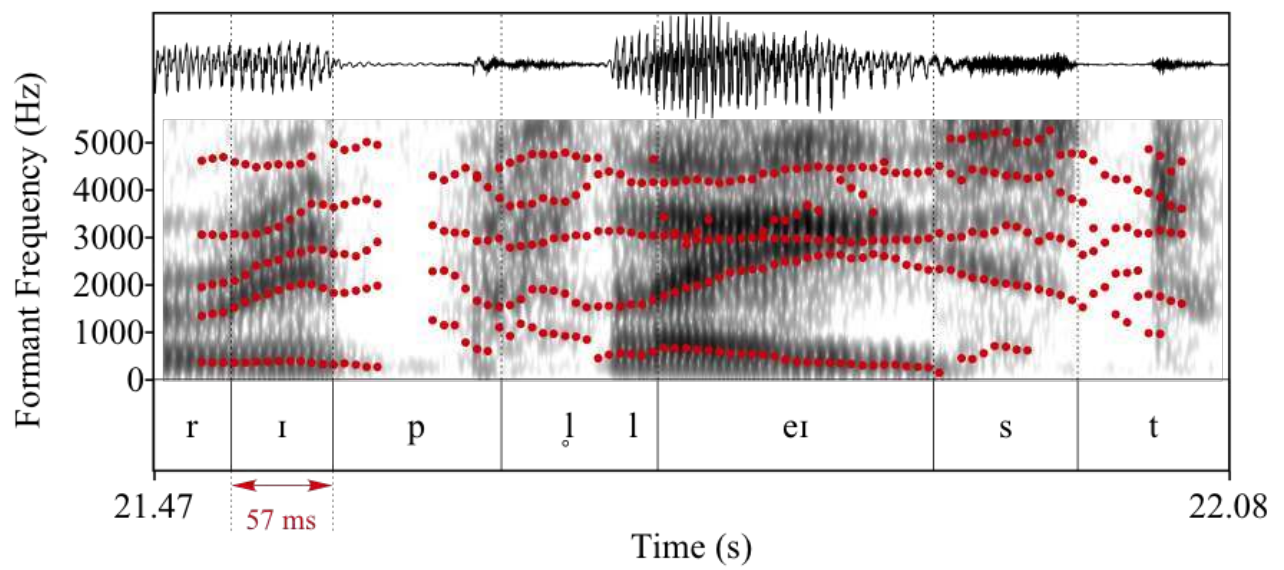

The fact that the two verbs (re-place and replace) are very close as far as pronunciation is concerned may lead to semantic ambiguity and it is only because remove is in the same utterance that the hearer grasps the right meaning of the verb. It should be added that this example was drawn from a news report and that the journalist was probably reading a text. This might explain why she pronounced the verb with a reduced prefix as replace is more commonly used in everyday English than re-place. This example raises the problem of scripted oration as the ambiguity between these two verbs will probably not occur in spontaneous speech.

The same ambiguity may arise in other pairs of verbs such as re-form / reform (see Videau \& Hanote 2012) or defuse / diffuse as is the case in example (8): 
(8) Jeremy Hunt: But the reality is when you hear what we heard this week, it is totally heartbreaking. I mean, Staff Sergeant Schmidt who died last Saturday who diffused (sic) sixty-four bombs and then tragically lost his own life, these people are heroes. (BBC - Any Questions, November $6^{\text {th }}, 2009$ ) here was defused and not diffused. The misprint is linked to the way the verb was pronounced with a short and lax vowel (see figure 14) and not with the long and tense vowel that was expected according to the morphology and the semantics of the prefixed verb. This phonetically reduced form of the prefix led to an unintentionally ironic spelling of the prefixed verb which, in this context, might be problematic.

Figure 14: diffuse

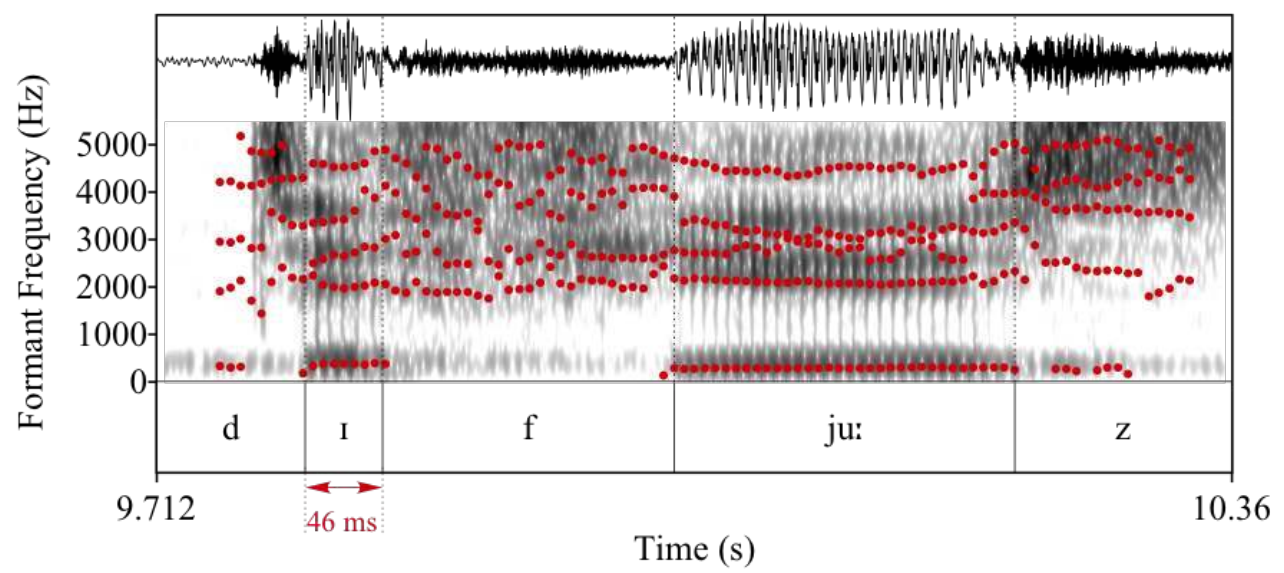

This misspelling may seem anecdotal but is in fact quite commonly found on radio websites in the following collocations (?diffuse bombs / ?diffuse a crisis). This is underlined on John Wells's blogis:

The pair diffuse (v.) - defuse is interesting. Although I use strong , di:- in the second myself, so that they are not homophones, many other people ${ }^{19}$ weaken the de- and not only pronounce the two words identically, di'fju:z, but get the meanings confused. While traditionally to diffuse is to spread and to defuse is to render (a bomb) safe, you do sometimes come across references to "diffusing" a tense situation. I would write "defusing".

In this context, only the general meaning of the utterance helps the hearer to interpret the prefixed verb correctly but there is a high risk of semantic ambiguity and misinterpretation of the message from the hearer.

\section{Prefixation and contrast}

We will now focus on various cases of contrast, either explicit or implicit, and show how inseparable prefixes can be made prominent despite their morphological and semantic opacity. 


\subsection{Explicit contrast}

31 Let us start by examining what we call explicit contrast, that is, utterances in which two antonymic prefixed words are contrasted. In cases of contrast, prefixes are often made prominent through a greater degree of stress, as explained by Fudge [1984: 164]:

[Prefixes] may receive nuclear stress (the most important stress in a sentence) if they are contrastively stressed; the following dialogue exemplifies this:

A It's probable that Peter will win.

B Really? I'd have thought that was very improbable ['Im,prbbəbl]. [Fudge, 1984: 164]

The same kind of process as that described by Fudge occurs in the following authentic example from the American National Public Radio (NPR) where the separable prefix mis- is prominent in misperception, reinforcing the contrast with perception in the context.

(9) Noah Adams: Exercise can be hard on the joints at least that's a common perception -make that misperception. (NPR - All things Considered, September $4^{\text {th }}, 2009$ )

Figure 15: perception / misperception

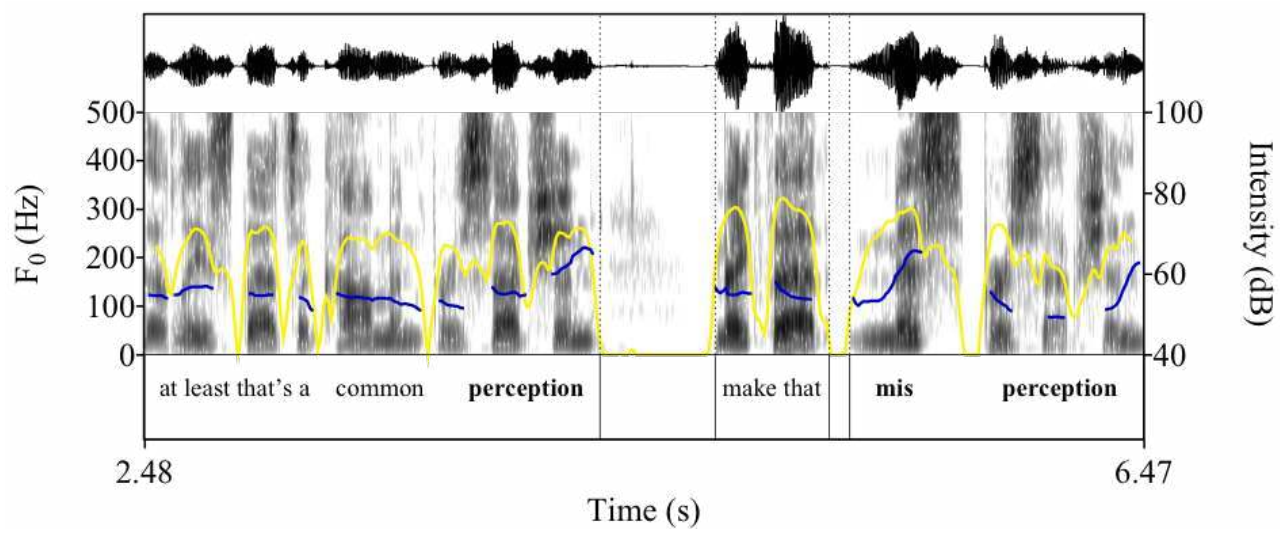

As shown in figure 15 , there is high intensity on the prefix mis-, associated to a large risefall movement of the pitch, both being the markers of a stress-shift on the prefix which not only bears primary stress but is also the nuclear element of the intonation phrase. Short pauses before and after the prefix also reinforce its prominence and emphasize the contrast between the two antonyms ${ }^{20}$.

Contrast is often mentioned by morpho-phonologists who study the pronunciation of prefixed words. Indeed, contrast often triggers a shift in stress onto the prefix, as explained by Bauer [1983: 124]:

Under exceptional circumstances, such as contrast or emphasis, [...] prefixes can take full stress: so that re'type would normally have secondary stress on the prefix, but in a sentence like I know you've already typed this once, but you made so many mistakes that I want you to retype it, the primary stress can fall on the prefix: 'retype.

Although Bauer uses an example containing a meaningful separable prefix (type/retype), we shall see that various types of contrast can trigger focus on inseparable prefixes that are not always productive and/or semantically analysable.

Let us now look at another example in which two inseparable prefixed words are contrasted: 
(10) Mitch Teich: You'd never confuse Northern Arizona with Vermont but tens of thousands of people from places like Phoenix, Los Angeles and Las Vegas, descend on Northern Arizona, then ascend the San Francisco peaks for some of the best fall foliage in the region. (NPR - All Things Considered, October $12^{\text {th }}, 2005$ )

Figure 16: descend/ascend

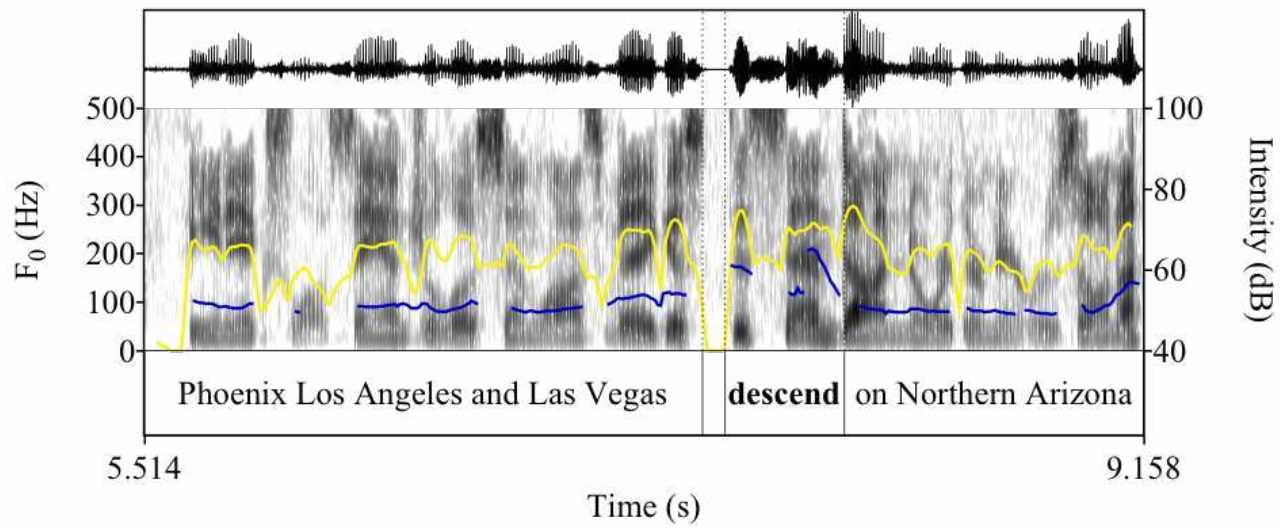

Figure 16: descend/ascend

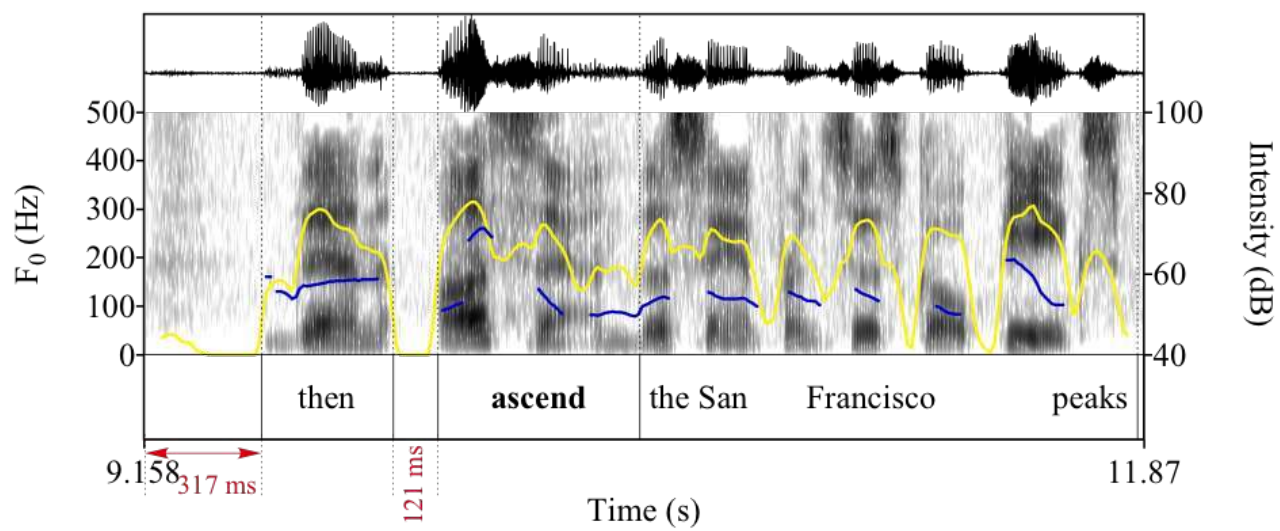

There is a contrast here between the two antonymic verbs descend and ascend ${ }^{21}$. The upper part of figure 16 shows that the syllable -scend in descend bears nuclear stress, as indicated by the falling intonation. The prefix is also pronounced with a short vowel, which is the "standard" pronunciation for this verb ([dI'send]). However, the lower part of the above figure shows that the prefix of the verb ascend receives contrastive stress. The word is preceded by a $121 \mathrm{~ms}$ pause which serves as a means of emphasizing what comes right after it, i.e., the prefix. Moreover, the vowel of the prefix has higher intensity and higher $\mathrm{F}_{0}$ than the following syllables. It is interesting to note that the pitch contour starts very low on the prefix (around $100 \mathrm{~Hz}$ ) before reaching much higher frequencies (around 250 $\mathrm{Hz}$ ) right before the fricative of the second syllable. Zooming in on the word (see figure 17) helps to understand this particular phenomenon: 


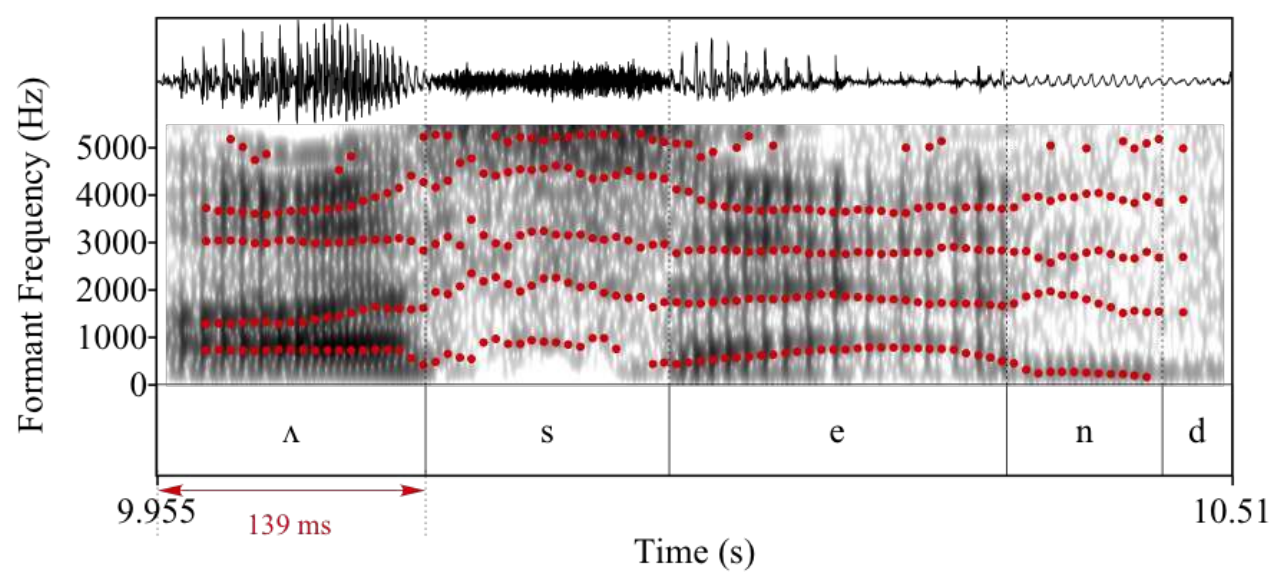

The spectrogram shows that the vertical striations of the first half of the vowel of the prefix are more spaced out than those of the second half of the vowel: this is a sign that the first part of the vowel is pronounced in a creaky voice, a phenomenon which is generally associated with a low $\mathrm{F}_{0}$. In the second part of the vowel, the striations come closer together, which is why the pitch is higher. What is also interesting on figure 17 is the duration of the vowel (139ms) as well as its quality: the formantic values of $F_{1}(720 \mathrm{~Hz})$ and $F_{2}(1300 \mathrm{~Hz})$ correspond to those of the lax vowel $[\Lambda]$. This modification in the pronunciation of the vowel is not surprising, as Bolinger [1961: 91] explains:

It usually happens that a leftwise shift onto a weak syllable forces a spelling pronunciation,

for the vowel is generally schwa, difficult to stress under these unusual circumstances.

One might expect the prefix to be pronounced with the lax vowel [æ], as predicted by Wells in LPD, when ascend is contrasted with descend. However, in this example, we are dealing with a case of restressing of schwa in American English, as Crannell [2010: 408] explains:

Restressing: The changing of a vowel due to a change in stress; frequently a schwa turns into a $[\Lambda]$ instead of retaining the original vowel. For example, in its restressed form, "was" becomes [wAz] instead of [waz] or [wDz].

This example shows that an inseparable prefix like ad-can be focused, despite the fact that it is no longer productive and semantically analysable in contemporary English.

\subsection{Implicit contrast}

41 Example 10 shows contrast between two antonymic verbs which, morphologically speaking, only differ by their prefixes (de-and $a d-$ ). This is why we choose to call it explicit contrast. However, speakers sometimes contrast prefixed words with various elements of an utterance, rather than with another prefixed word. This is what we call implicit contrast (although some linguists call it implied contrast), as mentioned in passing by Wennerstrom [1993: 311]:

Consider also that even an implied contrast may trigger focus on an analysable prefix, indicating that a direct juxtaposition of like stems is not the key factor:

a. Do you want a cigarette, or should we sit in NON-smoking?

b. OK, I see the good points, but what are the DIsadvantages?

This phenomenon appears in the following example: 
(11) Joe Palca: Next, Sigrun Hreinsdottir presented data from her ground stations that measure how the earth is moving around the volcano. Before the eruption, the earth ballooned out with magma that was ready to erupt. Now, the balloon appears to be deflating. (NPR - All Things Considered, April $19^{\text {th }}, 2010$ )

Figure 18: deflating

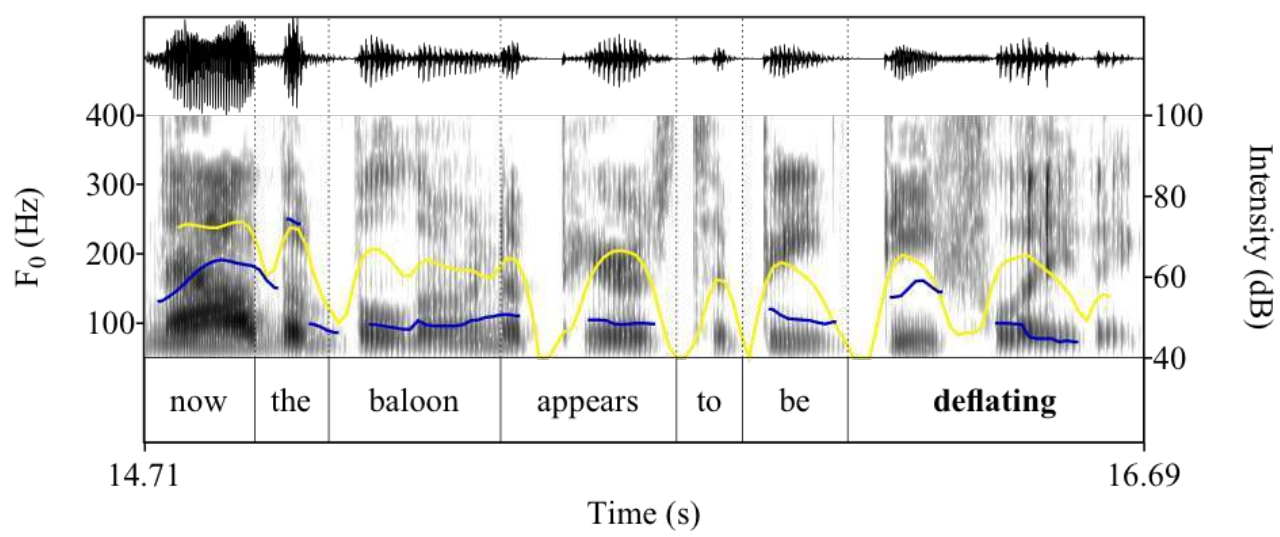

43 Figure 18 shows that the prefix bears contrastive stress. We can see a rise-fall movement and a much higher $\mathrm{F}_{0}$ on the prefix than on the preceding and the following syllables. It is to be noted that the antonymic verb inflate is nowhere to be found in this utterance. However, the phrasal verb ballooned out functions as a synonym of inflate and therefore triggers a contrast with deflating. It is also important to note that de-receives contrastive stress because it is semantically transparent, i.e., its meaning is analysable in deflate, despite the fact that -flate is a bound root with an opaque meaning in contemporary English. It is very unlikely that a semantically opaque prefix would receive contrastive stress in the case of implicit contrast, although we do not have data to test this hypothesis.

Let us examine another example:

(12) Yoki Noguchi: Rosen says a key reason the jobless rate has gone down is that some people have retired early, they've gone back to school, or they're so discouraged that they just gave up sending out resumes or knocking on doors. Rosen says it's the first time in a half a century [sic] that the labor force is decreasing. Baby boomers are exiting the workforce. (NPR - Morning Edition, September $2^{\text {nd }}, 2011$ ) 


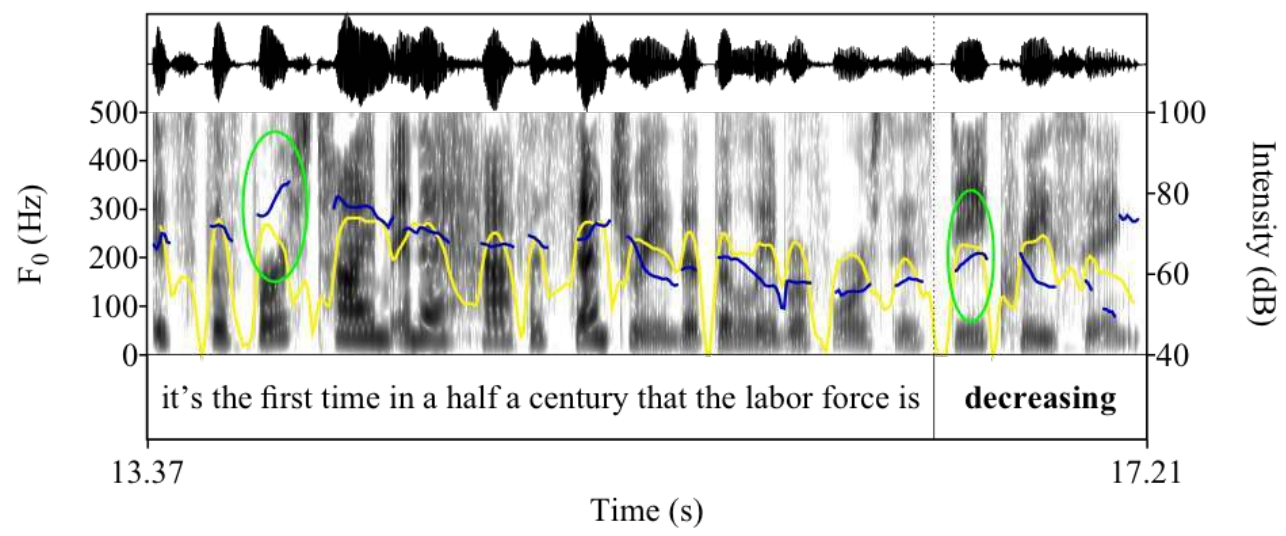

Figure 20: decreasing

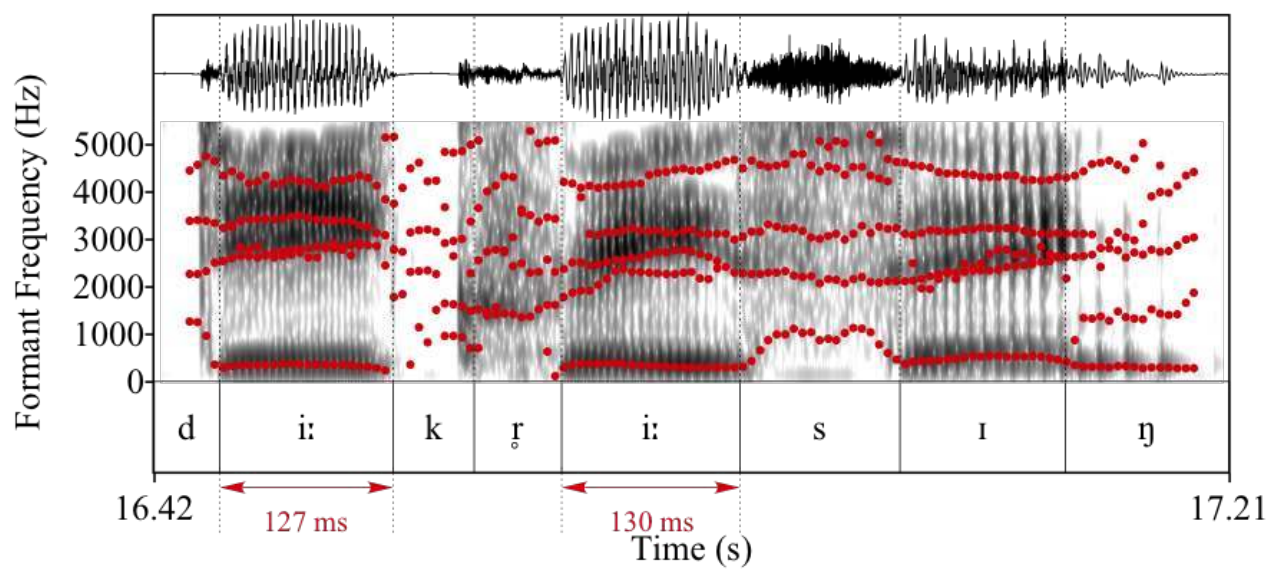

Here the inseparable prefix de- in the verb decreasing receives contrastive stress, as shown on figure 19. We can see a rise in the pitch contour on the prefix, followed by the beginning of a fall, which later continues on the second syllable -creas-. Figure 20 shows that the prefix is pronounced with a fairly long vowel (127ms), a duration that is comparable to that of the second vowel of the word (130ms). The formantic values of the vowel of the prefix $\left(\mathrm{F}_{1}=350 \mathrm{~Hz}\right.$ and $\left.\mathrm{F}_{2}=2615 \mathrm{~Hz}\right)$ indicate that the vowel is tense [i:].

The antonym increase does not appear in the utterance, nor do any of its synonyms, as was the case in example (11) (balloon out $\sim$ inflate). However, we can say that a contrast is construed by the clause It's the first time in a half a century... [sic]. The speaker implies that the process denoted by the verb decrease contrasts with what is usually the norm, i.e., the validation of the predicative relation <labor force - increase . This is marked by a rising pitch movement on the prefix, as explained above, but also on the adjective first (see figure 19).

\subsection{Pseudo-contrast}

Finally, our spoken corpus includes a few examples of what we have decided to call pseudo-contrast, that is, utterances in which the speaker contrasts two elements that do not function as antonyms, as was the case in the previous examples. 
(13) Tom Burrel: So we haven't - you know, if you don't address issues, if you don't - if you have a cancer, if you have a tumor, you can't just wait for it to dissipate. It doesn't just go away. It gets passed down. And you have this illusion of progress, you know, or even a delusion of progress, that just doesn't take away the fact that after all of the efforts that have been made, we are still, as a people, at the top of just about every bad list (NPR - Talk of the Nation, March $18^{\text {th }}, 2010$ )

Figure 21: illusion/delusion

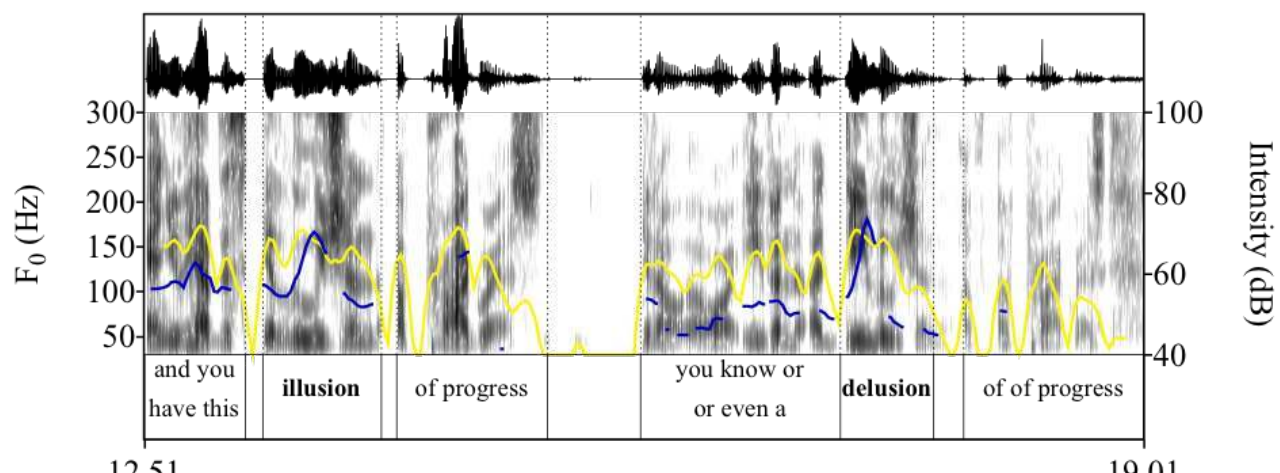

Time (s) in the fundamental frequency and the high intensity on the prefix de- of delusion. Moreover, the vowel of the prefix, which is noted [I] in pronunciation dictionaries (such as LPD), is affected by the shift in stress that occurs: the vowel has a duration of $111 \mathrm{~ms}$ and formant frequencies $\left(F_{1}=250 \mathrm{~Hz}\right.$ and $\left.F_{2}=2310 \mathrm{~Hz}\right)$ that indicate that it is the tense vowel [i:].

Figure 22: delusion

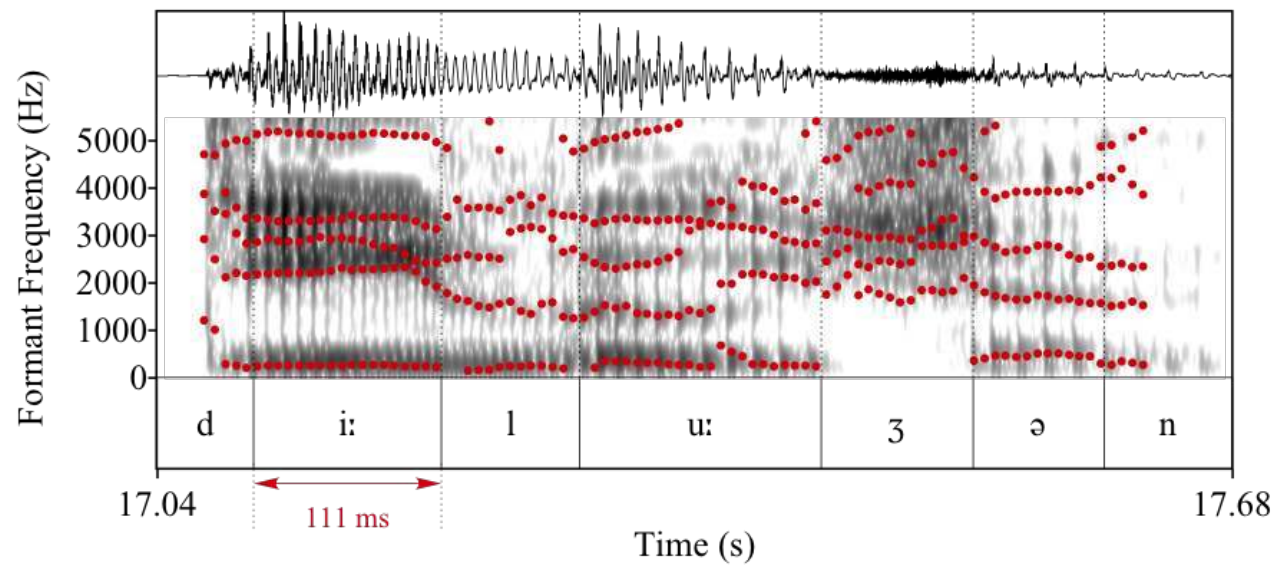


If the two words function as synonyms, how can we account for this contrast? Given the two nouns share the same root (-lusion), it seems that the speaker feels the need to emphasize their difference, i.e., the prefixed part. But we would also like to put forward the hypothesis that this morphological similarity triggers a semantic reactivation of the prefix de-in delusion, since de- is less "opaque" than il-/in-. This is not, however, the transparent and productive meaning the prefix has in contemporary English (privation or reversal), but rather, the following meaning: "In a bad sense, so as to put down or subject to some indignity" (OED). The appreciative modality carried by the prefix de- resurfaces through the contrast that is being made by the speaker. Indeed, the word delusion is more negatively connoted than the word illusion because of its greater degree of subjectivity and intentionality: the subject bears more responsibility of the wrong perception of a situation (progress in this example).

Now let us examine the following example, in which the journalist explains that a man, $\mathrm{Al}$ Argibay, is unhappy after being expelled from a gym after grunting during a weight training session:

(14) Tony Aiello: Correction's office Al Argibay grunted. Now, he's disgruntled with the gym, and its manager. (CBS News, November, 2006)

Figure 23: disgruntled

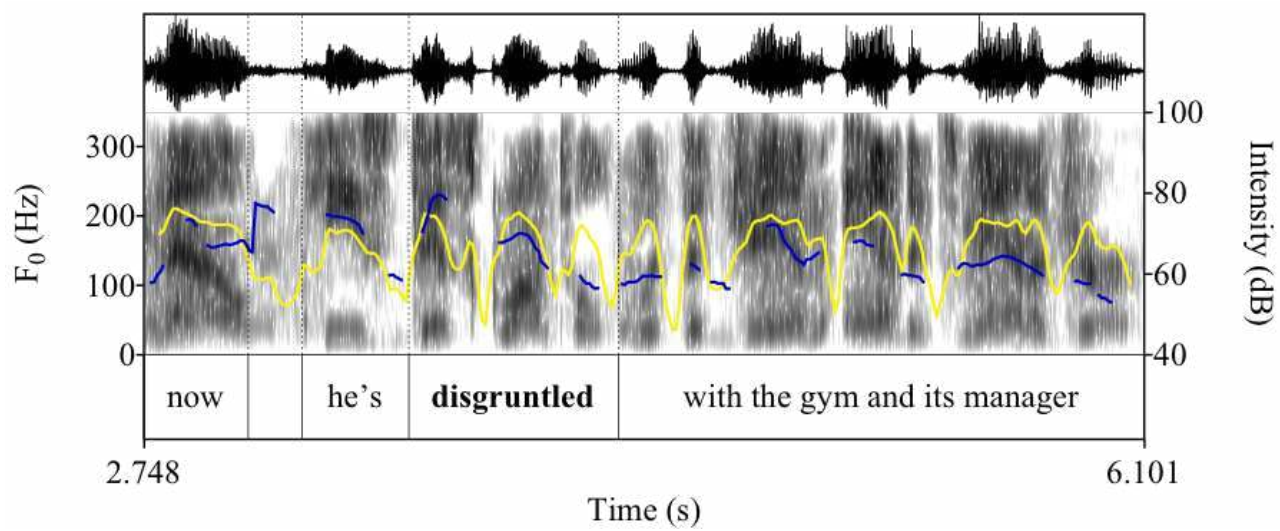

The speaker contrasts grunted and disgruntled, a verb and an adjective that share no semantic relationship whatsoever. However, the two words strongly resemble one another, since grunt and gruntled only differ by the [1] that appears in the final syllable of the latter. The speaker uses this resemblance to create a humorous contrast between the two words. The pun and the play on the prefix are made even more humorous by the fact that the word "*gruntled", without its "negative prefix", does not exist. The contrast between the two words is phonetically marked on the prefix dis-, as shown in figure 23, by a steep rise in pitch.

Prefixes, whether morphologically and semantically transparent or opaque, can be made prominent through contrast. In the final section, we shall see that extra-linguistic parameters, particularly pragmatic factors, also need to be taken into account when dealing with the pronunciation of prefixes in speech. 


\section{Pragmatic focalisation and stress shift}

54 In spoken discourse, prominence of prefixes in prefixed words does not occur only for contrastive purposes but is also possible in other contexts as shown in example (15):

(15) Tony Blair: One of the things I do in the book is to correct some of the... the... the... the really very exaggerated figures as to what's happened in the conflict and draw attention -this is based on the international Red Cross figures- er draw attention to the fact that of those that have died -and there's far too many of course- the vast bulk have been killed by sectarians and terrorists.

Journalist: We do know that Al Qaida increased their activities in Iraq after the war so those people may have died as a result of terrorism but that terr orism was there as an indirect result of your decisions. (Tony Blair, Interview on BBC Radio 4)

Some syllables, italicized in the example above, are made prominent through intensity and/or pitch variations, either stressed syllables of lexical words as in terrorism or function words like the preposition of or the auxiliary have which have not undergone phonetic reduction. But we will focus here more precisely on the prefix in- in the prefixed adjective indirect (indirect results).

Figure 24: indirect

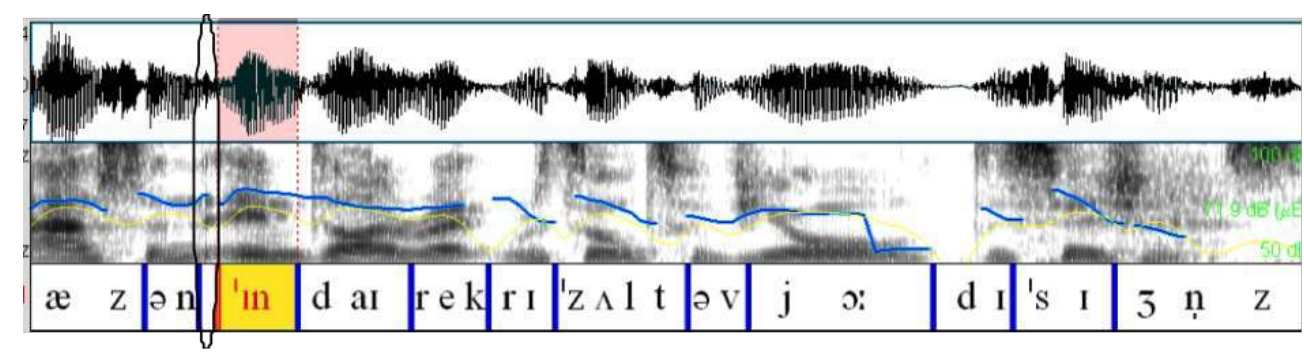

As shown in figure 24, the prefix is made prominent through high pitch and a rise-fall movement on the first syllable of the adjective which is the mark of a stress shift and through the presence of a glottal stop which prevents the linking process between the determiner an and the adjective indirect from taking place. Contrary to the examples dealt with in section 2, there is no particular explicit contrast with an antonym in the context here (direct vs. indirect results); the prominence of the prefix is due to the strategy of the journalist who seems to question (but not directly) the former Prime Minister's policy towards Iraq. Thus, prominence here is not linked to morphology or semantic disambiguation (section 1) nor to contrast within the utterance (section 2) but to interpersonal relations as mentioned by Wennerstrom [1993: 313-4]: "any syllable can be made prominent for metalinguistic purposes such as repair, clarification for the hearer or a stylistic effect". It can thus be characterized as 'pragmatic' prominence. This seems to be the case here as in the following example:

(16) Presenter: David Waterman organized a party with a pirate theme for Madeleine, his 8-year-old daughter. With cutlass wielding youngsters running around in eye patches, he thought a $5 \times 3$ foot skull and crossbones flag would add the perfect finishing touch. Hung outside, what other kind of flag would you have? The Mirror says, it reports the story too, that killjoys 
from the local council, wouldn't you believe it, have intervened after a complaint because the Jolly Roger is apparently covering outdoor advertisements. The paper says that the disbelieving Davis, the parent, is digging in his heels and he's going to pay for an advertising permit on a point of principle. (BBC - What the Papers Say, May $\left.7^{\text {th }}, 2007\right)$

Figure 25: disbelieving

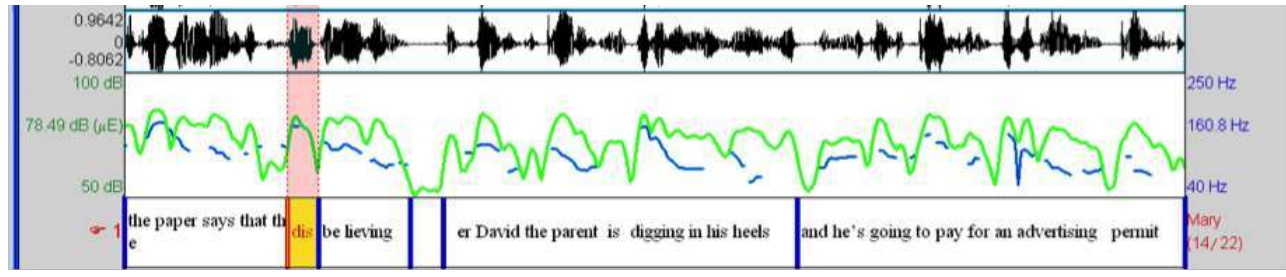

In this example drawn from a press review, the prefix dis- is prominent. This is shown through segmental and suprasegmental markers. As far as segmental parameters are concerned, there is no vowel lengthening (closed syllable) and there is no particular lengthening of the period of silence preceding the release phase in the pronunciation of the initial plosive [d], but there is a long duration of the fricative [s] and the following [b] is devoiced. As far as suprasegmental parameters are concerned, figure 25 shows that the pitch is higher on the prefix than on the following syllables. As in the previous example, these are the acoustic parameters of a stress shift in the prefixed word.

Figure 26: disbelieving

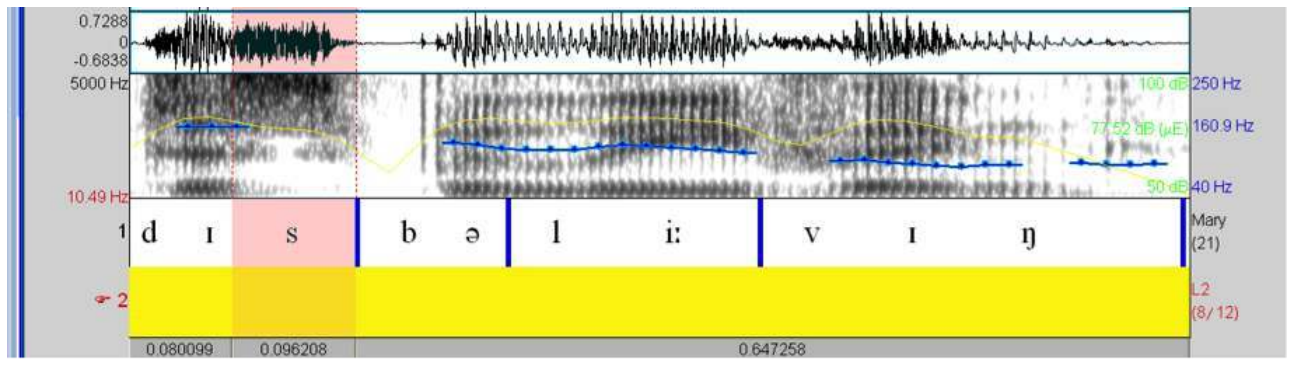

Here again, there is no contrast between two words in the immediate context. It should also be noted that the journalist is quoting the Daily Mirror (the paper says that...), but the prominence which might be considered as a form of appreciative modality is linked to the speaker's choice, i.e., the journalist who insists on the state of mind of David Waterman and probably also stresses the absurdity of the situation.

(17) Jeremy Hunt: Look, when MPs were running their own rules for expenses and allowances, we lost the public's trust. The solution is to get someone independent to do it. We have that independent person. We have to accept what they say. No ifs, no buts.

Jonathan Dimbleby: Even if there seem to be some natural injustices in the process?

Jeremy Hunt: There will be things that we don't like in it. ( $B B C$ - Any Questions, November $6^{\text {th }}, 2009$ )

In the example above, the prefix in- in injustice is made prominent not particularly through suprasegmental factors (there is the same intensity on both the prefix and the root and no particular movement in the $\mathrm{F}_{0}$, see figure 27) but through segmental factors, 
especially the length of the nasal [n] which lasts 152ms (see figure 28), which is fairly high for a nasal.

Figure 27: injustices (suprasegmental)

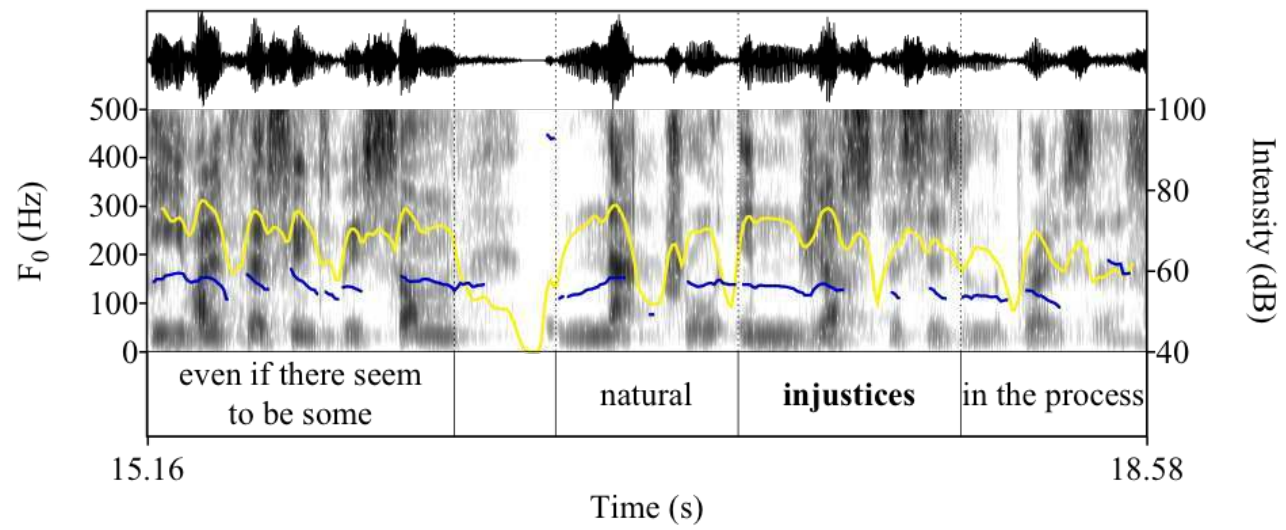

Figure 28: injustices (segmental)

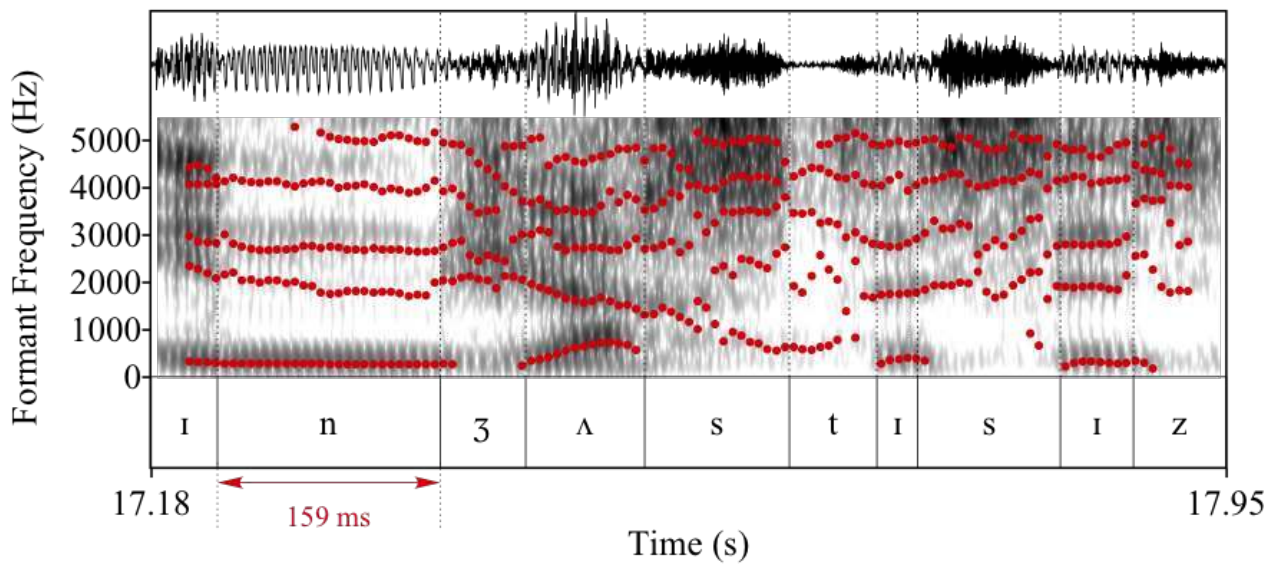

As in the previous examples, the reason for the prominence of the prefix may be questioned. It does not seem to be linked to the necessity of disambiguation as there is no possible semantic ambiguity between injustice and justice (justice is indeed uncountable, thus it cannot take the plural). The prominence may be linked to the will of the speaker to make an implicit contrast with justice but it seems to us that it is not the case here and that the prominence of the prefix is more likely to be linked to interpersonal relations. It should be noted that the prominence of the prefix is also reinforced by the pause between the determiner some and the adjective natural, maybe to highlight the unusual combination of the adjective natural and the noun injustices or simply to make the coutterer react to this particular combination and this is exactly what happens: the coutterer reacts by answering 'there will be things we don't like in it' with the modal will being particularly prominent in the utterance (it is highly probable that...) and the notion of natural injustices being rephrased in the following words: 'things we don't like'.

Let us finally examine the verb improve ${ }^{22}$ formed with an inseparable prefix, unlike the previous examples in which the words were formed with separable prefixes. 
(18) Jonathan Dimbleby: Do you believe that you can be certain that living standards will relatively improve as a result of independence? (BBC - Any Questions, January $13^{\text {th }}, 2012$ )

Figure 29: improve (suprasegmental)

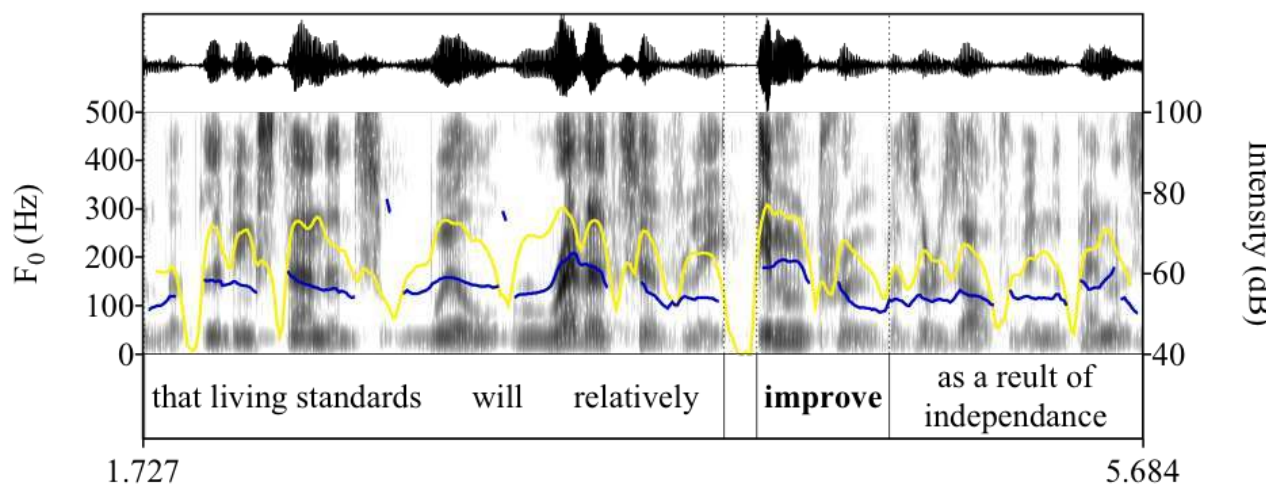

Time (s)

Several acoustic cues show that the prefix is made prominent in this utterance. Firstly, as one can see in figure 29 , the verb is preceded by a $130 \mathrm{~ms}$ pause. This pause follows the adverb relatively which is also prominent in speech (see the $\mathrm{F}_{0}$ and intensity lines on its first syllable) and creates a break between two elements in the verb phrase which are closely linked one to another (modifying adverb and the verb form). Before the pause, the $\mathrm{F}_{0}$ is fairly low on the last syllable of the adverb relatively, while it is much higher on the prefix. The intensity also reaches its peak on the prefix.

Figure 30: improve (segmental)

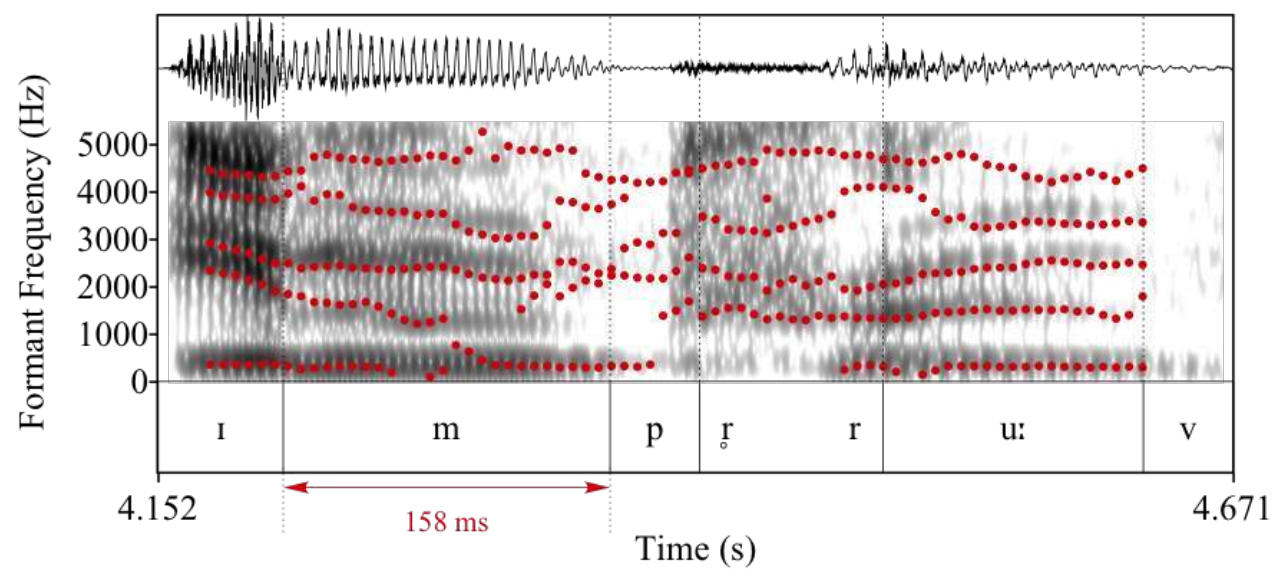

At the segmental level, the duration of the nasal [m] of the prefix reaches $158 \mathrm{~ms}$, which is -as in the preceding example- fairly high for this type of consonant ${ }^{23}$. What is striking here is that the prefix im-is an inseparable prefix which does not show any kind of semantic transparency in this word and which cannot be contrasted with any other prefix in the context. Its prominence in this example can only be accounted for by pragmatic focalization and has to be linked to other linguistic and prosodic markers in the utterance, which is highly modalised: a/ it is a question and the speaker relies on his interlocutor to confirm the assertion (do you...?) or not and b/ there are other typically modalising elements, such as the verb believe (do you believe), the modal can and the 
adjective certain (that you can be certain), as well as the adverb relatively. The speaker (journalist) seems to be cautious and very doubtful regarding the content of the utterance. It should be added that other syllables in the utterance are given prominence in relation to its content and the pragmatic strategy of the speaker (Do you believe that you can be certain that living standards will relatively improve as a result of independence?).

\section{Conclusion}

Morphophonology in itself often proves unsatisfactory to explain the various phonetic realizations of prefixed words in speech (whether with separable or inseparable prefixes). Using contextualized examples, we have shown that there is a close interaction between morphology, semantics, syntax and pragmatics and that a mere distinction between separable prefixes and inseparable prefixes may be inadequate. Indeed, our data suggest that the prefixes in many words whose morphological structures are identical (i.e., words with separable prefixes) show various degrees of prominence in speech. Similarly, when they belong to words with completely different morphological structures, some separable prefixes and inseparable prefixes may show no difference in prominence whatsoever. It is therefore necessary to take other parameters into account.

Semantic transparency is an important factor to consider when dealing with the pronunciation of prefixed words. Words such as demothing (3) or unfriend (4) have the same morphological structure as verbs like decode (1) or rebuild (2), but they show greater transparency, as they are either coined in speech or recently formed words. The hearer generally knows the root of the word (moth and friend). Therefore, the speaker tends to make the prefix more prominent.

It is also crucial to take the syntactic context of the utterance into account, particularly in the cases of contrast or repetition. Inseparable prefixes, such as ad-in ascend (10), or de- in deflate (11), decrease (12) or delusion (13) can receive the same degree of stress (contrastive stress) as a separable prefix such as mis- in misperception (9). This shows that separable prefixes and inseparable prefixes can be placed on the same level, despite their morphological differences.

The extra-linguistic context of the utterance has also proved to be of importance when dealing with the prominence of prefixes, or lack thereof. Both separable prefixes and inseparable prefixes can be made prominent for pragmatic purposes, as is the case in indirect (15), disbelieving (16) or improve (18), in which appreciative modality as well as the relationship between the speaker and the co-utterer are determining factors in accounting for the pronunciation of these words. In other examples, the extra-linguistic context can lead to the destressing of the prefix, as in rebuild (6). Such a phenomenon can be seen as unproblematic in such a case, as the vowel reduction of the prefix does not lead to semantic ambiguity, but in other cases, such as replace (7) and defuse (8), the destressing of the prefix can cause confusion for the hearer. Examining the phonetic realization of prefixed words in naturally occurring speech thus shows that while the morphological and semantic principles governing the pronunciation of prefixes in contemporary English remain essential, they need to be articulated with a set of contextual and/or pragmatic parameters, in order to account for the wide range of variation that can be observed. 


\section{BIBLIOGRAPHY}

\section{Theoretical textbooks}

ARONOFF Mark, 1976, Word Formation in Generative Grammar, Cambridge \& Massachussets: MIT

Press.

BAUER Laurie, 1983, English Word-Formation, Cambridge University Press.

BOLINGER Dwight, 1986, “Contrastive Accent and Contrastive Stress”, Language, Vol. 37, n¹, 83-96.

CRANNEL Kenneth, 2010, Voice and Articulation, Boston: Wadsworth.

DESCHAMPS Alain, FOURNIER Jean-Michel, DUCHET Jean-Louis \& O'NEIL Michael, 2004, English

Phonology and Graphophonemics. Gap \& Paris: Ophrys.

DUCHET Jean-Louis, 1994, Code de l'anglais oral, Gap \& Paris : Ophrys.

FOURNIER Jean-Michel, 1996, « La reconnaissance morphologique », in DUCHET Jean-Louis, FOURNIER Jean-Michel, HUMBLEY John \& LARREYA Paul (eds.), sème colloque d'avril sur l'anglais oral, Université de Paris-Nord : CELDA, diffusion APLV : 45-75.

FUDGE Erik, 1984, English Word-Stress, London: Allen \& Unwin Limited.

GUIERRE Lionel, 1979, Essai sur l'accentuation en anglais contemporain, Thèse d'état, Université Paris VII.

GUIERRE Lionel, 1984, Drills in English Stress-Patterns, Paris: Armand Colin - Longman.

GuYOT-TALBOT Anne, 2003, Les préfixes et la reconnaissance morphologique, Thèse de doctorat, Université Paris VII.

HANOTE Sylvie, VIDEAU Nicolas, zUMSTEIN Franck \& CARRÉ Philippe, 2010, « Les préfixes anglais unet $d e$ - : Etude phonétique et acoustique ", in Corela - Parole.

http://corela.edel.univ-poitiers.fr/index.php?id=1081

MOORE Susan, 2005, «L'intensification et la comparaison comme stratégies de discours : quel rapport avec les paramètres acoustiques ? ", in MÉRILLOU Catherine (dir.), Intensité, comparaison, degré - 2, Travaux linguistiques du Cerlico n¹8, Rennes : Presses Universitaires, 211-228.

MOORE Susan, 2012, “The markers of Focalization in oral English”, in CAPPEAU Paul \& HANOTE Sylvie (dir.), Focalisation(s). Saillance dans les langues : lexique, syntaxe, prosodie, Rennes : Presses Universitaires de Rennes, 59-81.

PAILLARD Michel, 2000, Lexicologie contrastive anglais-français. Formation des mots et construction du sens, Gap \& Paris : Ophrys.

TOURNIER Jean, 1985, Introduction descriptive à la lexicogénétique de l'anglais contemporain, Paris Genève : Champion - Slatkine.

TOURNIER Jean, 1991a, Précis de lexicologie anglaise, Paris : Nathan.

TOURNIER Jean, 1991b, Structures lexicales de l'anglais, Guide alphabétique, Paris : Nathan. 
TREVIAN Ives, 2003, Morphoaccentologie et processus d'affixation de l'anglais, Bern : Peter Lang.

TREVIAN Ives, 2010, Les affixes anglais, productivité, formation de néologismes et contraintes combinatoires : De la diachronie à la synchronie, Bern : Peter Lang.

VIDEAU Nicolas \& HANOTE Sylvie, 2012, «Préfixation et focalisation », in Focalisation(s). Saillance dans les langues : lexique, syntaxe, prosodie, Collection 'Rivages Linguistiques', Rennes : Presses Universitaires de Rennes, 35-58.

VIDEAU Nicolas, 2013, Préfixation et phonologie de l'anglais : analyse lexicographique, phonétique et acoustique, Thèse de doctorat, Université de Poitiers.

WENNERSTROM Ann, 1993, "Focus on the Prefix: Evidence for Word-Internal Prosodic Words", Phonology, Vol. 10, n², Cambridge University Press, 309-324.

\section{Dictionaries}

Longman Dictionary of Contemporary English, London: Pearson Longman, 2009.

Oxford English Dictionary, http://www.oed.com/.

WELLS John C., Longman Pronunciation Dictionary, $1^{\text {st }}, 2^{\text {nd }}$ and $3^{\text {rd }}$ editions, London: Longman, 2008

[1990, 2000].

\section{Corpus}

BBC Radio 4: http://www.bbc.co.uk/radio4/

BNC: http://corpus.byu.edu/bnc/

National Public Radio: http://www.npr.org/

\section{Blog}

WELLS John C.: http://phonetic-blog.blogspot.com/

\section{NOTES}

1. In nouns, however, inseparable prefixes often bear primary stress ('promise, 'abstract, etc.). See for instance Duchet [1994] and Deschamps et al. [2004].

2. See Videau [2013: 32-40].

3. http://www.bbc.co.uk/radio4

4. http://www.npr.org/

5. http://www.fon.hum.uva.nl/praat/

6. $82 \mathrm{~dB}$ on the prefix de-and $85 \mathrm{~dB}$ on the root code for the word decode; $65 \mathrm{~dB}$ on the prefix re-and $72 \mathrm{~dB}$ on the root build for rebuild.

7. Formants data for [i:] in de- $: \mathrm{F}_{1}=238 \mathrm{~Hz}$ and $\mathrm{F}_{2}=2430 \mathrm{~Hz}$; formants data for [i:] in re-: $\mathrm{F}_{1}=345 \mathrm{~Hz}$ and $\mathrm{F}_{2}=2270 \mathrm{~Hz}$.

8. Duration of the vowel [i:] in de-: $135 \mathrm{~ms}$; duration of the vowel [i:] in re-: $97 \mathrm{~ms}$.

9. $=225 \mathrm{~ms}$.

10. The speaker refers to the reality television game show series 'I'm a Celebrity, get me out of here'. 
11. Commonly used both literally and figuratively in the sense of "remove the faults from a machine, a system or a computer programme".

12. $\mathrm{F}_{1}=305 \mathrm{~Hz}$ and $\mathrm{F}_{2}=2650 \mathrm{~Hz}$; these data are characteristic of the front and high vowel [i].

13. $140 \mathrm{~ms}$ in demothing and $180 \mathrm{~ms}$ in decreaturing. These data may be compared to the length of the vowel under primary stress in decreaturing $=100 \mathrm{~ms}$.

14. This word was declared Word of the Year in 2009 by the New Oxford American Dictionary.

15. http://www.oed.com/

16. The prefix is so short and reduced that we were not able to determine where the boundary between $[\mathrm{r}]$ and $[ə]$ should be placed.

17. As shown in the spectrogram (figure 13), the first part of the lateral consonant $/ 1 /$ is devoiced because it follows the voiceless plosive [p]. It then becomes voiced right before the diphthong of the root. This is why we have chose to use [1] and [1] in the transcription.

18. http://phonetic-blog.blogspot.com/

19. The data of our corpus seem to confirm this statement as 18 out of the 19 occurrences of defuse are pronounced [dI'fju:z].

20. The prominence of prefixes in speech occurs not only on separable prefixes but is also possible when the prefix is inseparable in pairs such as increase / decrease or accelerate / decelerate (see below).

21. Both verbs are formed with the same Latin root '-scandere' (= to climb) and two antonymic prefixes $a d$ - and de- (as- being an assimilated form of Latin $a d$ - before $<\mathrm{s}>$ or $<\mathrm{c}>$ ).

22. From Old French em + prou profit (from late Latin prode), later infl. by prove, verb. Cf. approve verb. (Shorter Oxford English Dictionary)

23. It should be noted here that the speaker in examples (16) and (17) is the same person, the journalist Jonathan Dimbleby.

\section{ABSTRACTS}

The pronunciation of prefixed words in English has often been defined in terms of morphology only (see for instance Guierre [1979], Fournier [1996] or Guyot-Talbot [2003]) as follows: a separable prefix bears primary or secondary stress according to its syntactic category whereas an inseparable prefix is unstressed and its vowel is reduced. This definition appears to be unsatisfactory as far as the pronunciation of prefixed words in normal speech is concerned. Other parameters have yet to be taken into account. Based on the acoustic analysis of an oral corpus drawn from the radio ( $B B C$ Radio 4 for British English and National Public Radio for American English), this paper investigates the pronunciation of prefixed words taking into account not only morphophonology but also the semantic relationship between the two elements of the word (prefix and root) and the linguistic and extralinguistic contexts in which the prefixed words are uttered. For instance, we shall show that the relationship between the speaker and his/her co-speaker [5especially in cases of explicit or implicit contrast, of focalization, etc.- have an impact on the pronunciation of prefixed words in normal speech. The prefix may then bear not only word stress but also pitch accent and be prominent in discourse depending on the speaker's intention.

La prononciation des préfixés en anglais est souvent définie par des règles basées strictement sur la morphologie : un préfixe séparable se verra doté d'un accent (principal ou secondaire selon la 
catégorie syntaxique du mot) alors qu'un préfixe inséparable sera inaccentué et réduit. Or, il s'avère que cette distinction morphologique n'est pas suffisante pour rendre compte de la prononciation des préfixés en discours. Le préfixe pourra alors porter non seulement l'accent de mot mais également un accent mélodique qui le rendra proéminent dans le discours pour des raisons de contraste, d'emphase, de focalisation, etc. À partir de l'analyse acoustique d'un corpus oral de 80000 mots (environ $8 \mathrm{~h}$ d'audio) et qui comprend différents types de documents (bulletins d'information, interviews, débats, etc.), nous envisagerons les différents paramètres déterminants dans la prononciation des préfixés au-delà de l'aspect strictement morphophonologique en prenant en compte la transparence sémantique (notamment lorsqu'il existe des paires antonymes du type ascend / descend, accelerate / decelerate, decrease/increase, etc.), mais aussi et surtout les relations intersubjectives et le contexte.

\section{INDEX}

Mots-clés: linguistique, lexicologie, prosodie, sémantique, préfixation, néologisme

Keywords: linguistics, lexicology, prosody, semantics, prefixation, neologism

\section{AUTHORS}

\section{NICOLAS VIDEAU}

Université de Poitiers, Laboratoire FoReLL (EA 3816)

nicolas.videau@univ-poitiers.fr

\section{SYLVIE HANOTE}

Université de Poitiers, Laboratoire FoReLL (EA 3816)

sylvie.hanote@univ-poitiers.fr 